The last interglacial climate comparing direct and indirect impacts of insolation changes

Pedersen, Rasmus A.; Langen, Peter L.; Vinther, Bo M.

Published in:

Climate Dynamics

DOI:

$10.1007 / \mathrm{s} 00382-016-3274-5$

Publication date:

2017

Document version

Publisher's PDF, also known as Version of record

Document license:

CC BY

Citation for published version (APA):

Pedersen, R. A., Langen, P. L., \& Vinther, B. M. (2017). The last interglacial climate: comparing direct and indirect impacts of insolation changes. Climate Dynamics, 48(9-10), 3391-3407. https://doi.org/10.1007/s00382016-3274-5 


\title{
The last interglacial climate: comparing direct and indirect impacts of insolation changes
}

\author{
Rasmus A. Pedersen ${ }^{1,2} \cdot$ Peter L. Langen ${ }^{2}$ Bo M. Vinther ${ }^{1}$
}

Received: 14 March 2016 / Accepted: 12 July 2016

(C) The Author(s) 2016. This article is published with open access at Springerlink.com

\begin{abstract}
The last interglacial climate was influenced by substantial changes in the annual insolation cycle that led to a warmer climate state with pronounced high northern latitude warming. We analyze the impact of the insolation changes 125,000 years before present using an equilibrium snapshot simulation with the EC-Earth coupled climate model at high spatial resolution. Using additional atmosphere-only simulations, we separate the direct impact from the changed insolation from the secondary contribution from changed sea surface conditions. These simulations are forced with a combination of last interglacial sea surface temperatures and sea ice conditions and pre-industrial insolation, and vice versa. The coupled simulation yields an annual mean global warming of approximately $0.5{ }^{\circ} \mathrm{C}$ compared to pre-industrial conditions. While the warming over the continents follows the annual cycle of the insolation anomalies, two regions exhibit persistent responses throughout the year: The tropical region exhibits lower temperatures and stronger monsoonal systems, while the Arctic region shows a warming of more than $2{ }^{\circ} \mathrm{C}$ in all seasons. The hybrid simulations reveal that the changed sea surface conditions dominate the response at high northern latitudes, including the North Atlantic region and Europe, while the direct insolation impact is more dominant in the tropics.
\end{abstract}

Rasmus A. Pedersen

anker@nbi.ku.dk

1 Centre for Ice and Climate, Niels Bohr Institute, University of Copenhagen, Juliane Maries Vej 30, 2100 Copenhagen, Denmark

2 Climate and Arctic Research, Danish Meteorological Institute, Copenhagen, Denmark
Keywords Last interglacial · Eemian · EC-Earth · General circulation model $\cdot$ Monsoon $\cdot$ AMOC

\section{Introduction}

The last interglacial (LIG; also known as the Eemian or MIS5e) lasted from 129 to 116 thousand years before present (ka). Changes in the orbital configuration and thus the insolation resulted in global warming of up to $2{ }^{\circ} \mathrm{C} \mathrm{com-}$ pared to pre-industrial conditions, with more pronounced warming at high latitudes (CAPE-Last Interglacial Project Members 2006; Masson-Delmotte et al. 2013; Capron et al. 2014). Due to the nature of the forcing, the last interglacial is not a perfect analogue for future greenhouse gas driven warming. Regionally, however, the LIG warming could be comparable to a future, warmer climate state. Future greenhouse gas warming is expected to result in polar amplification of the surface temperature response (Serreze and Barry 2011), which could resemble the pronounced high-latitude temperature response during LIG (e.g. Clark and Huybers 2009). The availability of paleoclimate information furthermore means that climate model simulations of the last interglacial are an opportunity to evaluate model performance outside of near-present day conditions, potentially leading to improved projections of future warming (OttoBliesner et al. 2006; Braconnot et al. 2012; Otto-Bliesner et al. 2013).

The LIG warming over the polar regions caused a reduction of the ice sheets, and a consequent sea level rise of 6-9 m above present-day level (Kopp et al. 2009; Dutton and Lambeck 2012; Dutton et al. 2015). While both the Greenland (GIS) and Antarctic ice sheets must have contributed to this sea level increase, existing studies present a wide range of ice sheet reconstructions. While the 
estimated contribution from GIS of 1.4-4.3 m implies a contribution from Antarctica, existing model and observational data is currently insufficient for a reliable quantification of the Antarctic ice sheet changes (Masson-Delmotte et al. 2013).

Several studies have investigated the last interglacial using climate models of varying complexity. Transient simulations usually rely on earth system models of intermediate complexity (Bakker et al. 2013, 2014), while general circulation models (GCMs) primarily are employed for equilibrium, snapshot simulations (Fischer and Jungclaus 2010; Govin et al. 2012; Lunt et al. 2013; Nikolova et al. 2013; Otto-Bliesner et al. 2013; Langebroek and Nisancioglu 2014). Recent model assessments find very low global annual mean warming during LIG, contrasting the proxy reconstruction estimate of 1-2 K warming (Masson-Delmotte et al. 2013; Otto-Bliesner et al. 2013). The latest IPCC report estimates a multi-model annual mean surface warming of $0.0 \pm 0.5 \mathrm{~K}$ (Masson-Delmotte et al. 2013), while Lunt et al. (2013) find warming in the Arctic and cooling in the African and Indian monsoon regions as the only robust annual mean results in their intercomparison of 14 models. Seasonally, the models consistently simulate warming over Northern Hemisphere continents during summer (June-July-August; JJA) and global cooling (except in the Arctic) during winter (December-January-February, DJF) (Lunt et al. 2013; Nikolova et al. 2013; Otto-Bliesner et al. 2013; Langebroek and Nisancioglu 2014). While these patterns agree qualitatively with proxy reconstructions, the models generally underestimate the magnitude of the changes (Braconnot et al. 2012; Masson-Delmotte et al. 2013; Lunt et al. 2013; Otto-Bliesner et al. 2013). Several models have the strongest warming occurring in the North Atlantic region as a consequence of retreating sea ice and changes in the ocean circulation (Fischer and Jungclaus 2010; Lunt et al. 2013; Nikolova et al. 2013; Otto-Bliesner et al. 2013).

Continued improvements of GCMs and increased availability and quality of proxy records (Capron et al. 2014; Govin et al. 2015) give reason for continued investigation of the last interglacial. Using the state-of-the-art EC-Earth climate model, we have designed a series of experiments to investigate the last interglacial climate and the mechanisms behind the warming. Specifically, we will assess how the indirect impact of the changed ocean conditions compares to the direct insolation response, and how the relative contributions vary regionally. Our experiments are single snapshot, equilibrium simulations forced with repeating $125 \mathrm{ka}$ boundary conditions. $125 \mathrm{ka}$ is near the peak insolation forcing at high northern latitudes and the precession optimum, where the insolation increase coincides with summer solstice. We thus expect $125 \mathrm{ka}$ to be near peak Arctic warming; the NEEM ice core (NEEM community members, 2013) indicates peak Greenland warming between 128 and $124 \mathrm{ka}$. Furthermore, $125 \mathrm{ka}$ is beyond the initial interglacial period where the climate was dominated by the changing ice sheets and ocean conditions. Sea level studies (e.g. Kopp et al. 2013) indicate sea level peaked near $125 \mathrm{ka}$, suggesting that the ice sheets were stabilizing. The impact of ice sheet changes and freshwater ocean forcing at this time should thus be limited, making it reasonable to exclude these changes from our model simulations.

The experiments are performed in high spatial resolution compared to similar paleoclimate experiments. The highest atmospheric model resolution in the Lunt et al. (2013) multi-model ensemble is T85 (corresponding to $1.4^{\circ}$ spatial resolution), whereas our experiments have a T159 spectral resolution (approximately $1.1^{\circ}$ spatial resolution). The atmospheric vertical resolution is similarly increased, as our setup has 62 levels in the vertical compared to only 26 in the T85 configuration (Lunt et al. 2013; Otto-Bliesner et al. 2013).

We describe the experiments and the climate model configuration in Sect. 2. In Sect. 3, we present the results of the simulations and assess the direct and indirect impacts of the insolation changes. The results are discussed and compared to proxy records in Sect. 4. Conclusions are presented in Sect. 5.

\section{Methods}

\subsection{Model configuration}

The model used for this study is the EC-Earth global climate model in the most recent version 3.1 (Hazeleger et al. 2010, 2012). EC-Earth consists of the IFS atmospheric model (cycle 36r4, European Centre for Medium-Range Weather Forecasts 2010) and the NEMO ocean model (version 3.3.1, Madec 2011) including the LIM3 sea ice model (Vancoppenolle et al. 2009). The atmospheric model has a T159 spectral resolution (roughly $1.125^{\circ} \times 1.125^{\circ}$ horizontal resolution) with 62 layers in the vertical. The NEMO ocean model is running on a tripolar ORCA grid with a horizontal resolution of approximately $1^{\circ}$ and has 46 levels.

In order to allow paleoclimate simulation, the model has been expanded with an option to modify the insolation according to any given orbital configuration. The insolation is internally calculated following Berger (1978) using the same code modification as Muschitiello et al. (2015).

\subsection{Experimental design}

The main experiment is a snapshot simulation of the last interglacial period at $125 \mathrm{ka}$, and follows the Paleoclimate Modelling Intercomparison Project PMIP3 protocol 
Table 1 Orbital parameters and atmospheric composition of the coupled simulations

\begin{tabular}{lllllll}
\hline & Eccentricity & Obliquity & Precession $\left(\widetilde{\omega}+180^{\circ}\right)$ & $\mathrm{CO}_{2}$ conc. $(\mathrm{ppm})$ & $\mathrm{CH}_{4}$ conc. $(\mathrm{ppb})$ & $\mathrm{N}_{2} \mathrm{O}$ conc. $(\mathrm{ppb})$ \\
\hline LIG & 0.040013 & $23.798^{\circ}$ & $307.14^{\circ}$ & 276 & 640 & 263 \\
PI & 0.016764 & $23.459^{\circ}$ & $100.33^{\circ}$ & 285 & 791 & 275 \\
\hline
\end{tabular}

$\widetilde{\omega}$ denotes the angle of perihelion relative to the vernal equinox (Berger 1978). The LIG experiment is following the PMIP3 last interglacial experiment design suggestions (125 ka experiment, PMIP3 webpage)

Fig. 1 Insolation anomalies [W $\mathrm{W}^{-2}$ ] in LIG compared to PI. Left panel displays zonal anomalies through the year, right panel the zonal annual mean. Time labels on the left panel mark the beginning of each month

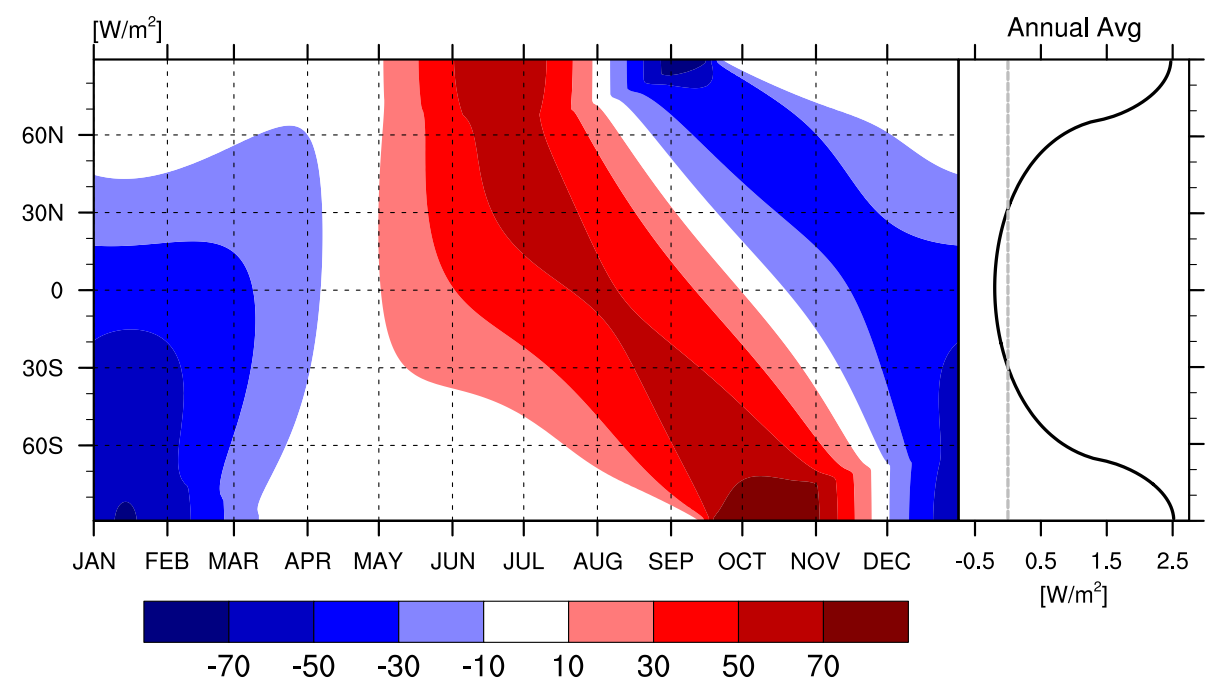

(PMIP3 webpage 2010; Braconnot et al. 2011, 2012). We focus on $125 \mathrm{ka}$, when high northern latitude temperatures are near peak LIG warming (NEEM community members 2013; Bakker et al. 2013) and the sea level stabilizing (Masson-Delmotte et al. 2013; Kopp et al. 2013) indicating that ice sheet retreat and related freshwater flux into the ocean is diminishing. In line with the PMIP3 125 ka experiment, the simulation is only forced by insolation changes and changes in the atmospheric gas composition, while the ice sheets and vegetation are kept unchanged. The last interglacial climate is compared to a pre-industrial control simulation, forced by insolation and atmospheric components from 1850. The atmospheric composition and orbital conditions for the last interglacial (LIG) and pre-industrial (PI) experiments are presented in Table 1. Figure 1 shows the resulting difference in insolation between PI and LIG.

Both simulations have been spun-up to a quasi-equilibrium state. The pre-industrial simulation has a total length of 850 years, and the LIG simulation has been run for a total of 480 years from a present-day state. Our analyses are based on climatologies over the last 100 years from each simulation. Statistical significance of changes is assessed using a two-sided Student's $t$ test (von Storch and Zwiers 2001)

To further investigate the dynamics behind the last interglacial warming, we have designed a series of simulations in an atmosphere-only version of the model (AGCM) based on the two coupled model experiments. The atmospheric model is unchanged, but the ocean model is replaced by prescribed sea surface boundary conditions (sea surface temperatures and sea ice). With these experiments, we aim to disentangle and compare the direct impact of the insolation changes and the secondary impact arising from changed sea surface temperature and sea ice conditions. Accordingly, two hybrid experiments have been designed based on the results from the coupled simulations. The first ("iL + oP") is forced by LIG insolation (and GHGs) and PI SST and sea ice conditions, while the other ("iP $+\mathrm{oL}$ ") conversely is forced by PI insolation and LIG SST and sea ice conditions. These simulations allow for an assessment of the impact of the insolation change without the contribution from the oceanic changes, and vice versa. An additional experiment ("iP + oP-ice") combines the LIG sea ice and PI SSTs to investigate the relative importance of the sea ice anomalies. To ensure consistency in the comparison, the pre-industrial and last interglacial climates states are resimulated in the atmosphere-only setup. These simulations ("iP + oP" and "iL + oL") are forced by the same insolation and GHG values as PI and LIG combined with the climatological SSTs and sea ice conditions obtained in the respective coupled simulation. The sea ice concentration is prescribed to the climatology from the coupled experiments, while the sea ice thickness is fixed to $1.5 \mathrm{~m}$ everywhere in all AGCM experiments. The sea ice thickness is 
Table 2 Boundary conditions for AGCM experiments

\begin{tabular}{lll}
\hline Experiment & Insolation and GHGs & SSTs and sea ice \\
\hline iP + oP & PI & PI \\
iL + oL & LIG & LIG \\
$\mathrm{iL}+\mathrm{oP}$ & LIG & PI \\
iP + oL & PI & LIG \\
iP + oP-ice & PI & PI SST + LIG sea ice \\
\hline
\end{tabular}

In the experiment names, the letter following " $\mathrm{i}$ " indicates the insolation conditions, while the letter following "o" indicates the oceanic conditions: "P" is PI and " $\mathrm{L}$ " is LIG

thus relatively low compared to the coupled experiments, but still thick enough to sufficiently insulate the atmosphere from the ocean.

Table 2 presents an overview of the AGCM simulations. The AGCM simulations all have a total length of 60 years, where the first 10 years are regarded as spin-up. The AGCM simulations exhibit less internal variability compared to the coupled simulations, and 50 years is thus sufficient to get widespread statistically significant changes.

All the results are presented in monthly and seasonal means following a fixed present-day calendar, although a calendar defining the seasons based on the orbital configuration could be more suitable (Joussaume and Braconnot 1997).

\section{Results}

\subsection{Coupled experiments}

The changed insolation in the LIG gives rise to a global annual mean warming of $0.5 \mathrm{~K}$. The annual mean warming is thus relatively high compared to the recent multi-model mean estimate of $0.0 \pm 0.5 \mathrm{~K}$ mean annual warming (Masson-Delmotte et al. 2013). Figure 2 nonetheless illustrates that the spatial pattern of the annual mean warming resembles the multi-model mean of previous LIG simulations (Lunt et al. 2013; Masson-Delmotte et al. 2013), albeit with stronger warming in the North Atlantic and stronger cooling in the tropics. The annual cycle of the insolation anomalies means that the seasonal insolation cycle is enhanced in the Northern Hemisphere (increase during summer; JJA) and reduced in the Southern Hemisphere (reduction during summer; DJF). The Northern Hemisphere annual mean warming is $0.7 \mathrm{~K}$, while the Southern Hemisphere mean is $0.2 \mathrm{~K}$. The Arctic region $\left(60-90^{\circ} \mathrm{N}\right)$ experiences a substantial year-round warming with an annual mean of $2.4 \mathrm{~K}$ and seasonal mean warmings ranging from $1.8 \mathrm{~K}$ in spring (March-April-May; MAM) to $2.9 \mathrm{~K}$ during summer (JJA). The seasonal mean near-surface air temperature anomalies are presented in Fig. 3 alongside the zonal mean insolation changes. Both winter (DJF) and summer (MAM) anomalies resemble the Lunt et al. (2013) multi-model mean, although we simulate stronger warming at high latitudes and in the North Atlantic. Comparison of the insolation forcing and the temperature response reveals that the overall response over the continents follows the annual cycle of the insolation anomalies. Nevertheless, some continental regions stand out with temperature response that cannot be attributed to a direct warming (cooling) from increased (decreased) insolation: High northern latitudes (especially Northern Asia and Greenland) and Europe exhibit warming, and the African and Indian monsoon regions exhibit cooling throughout the year. Consequently, we will give special attention to the responses over the polar regions, the North Atlantic region, and the tropics.
Fig. 2 Annual mean near-surface air temperature anomalies LIG-PI [K]. Shading denotes changes that are not significant at the $95 \%$ confidence level. Note the irregular spacing of the color bar

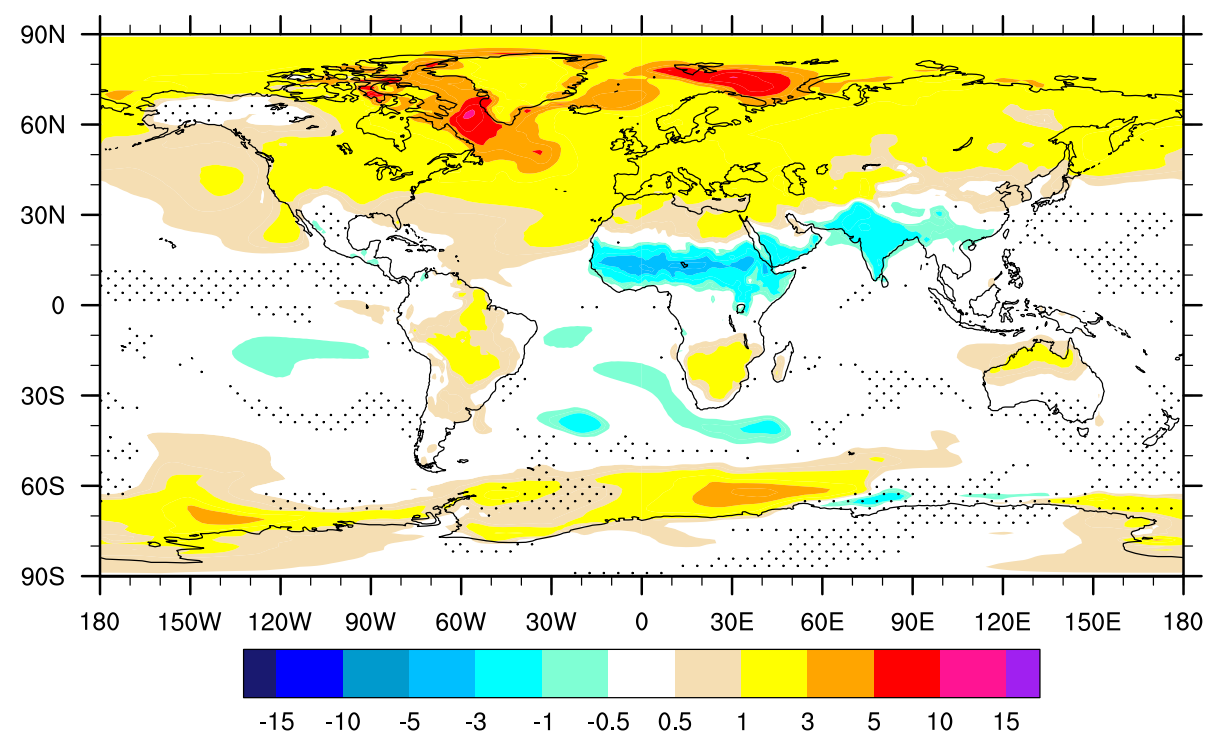




\section{DJF}

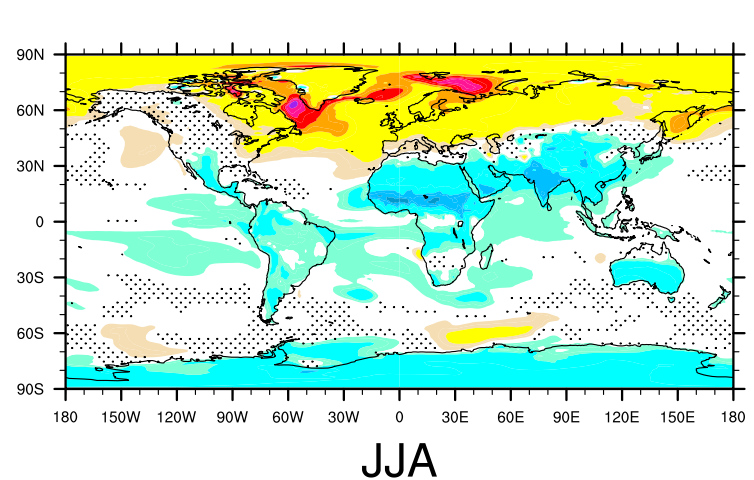

JJA
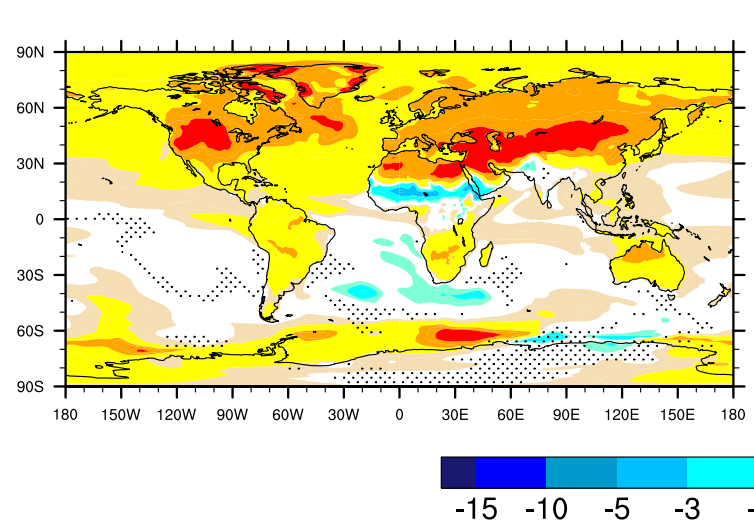

MAM
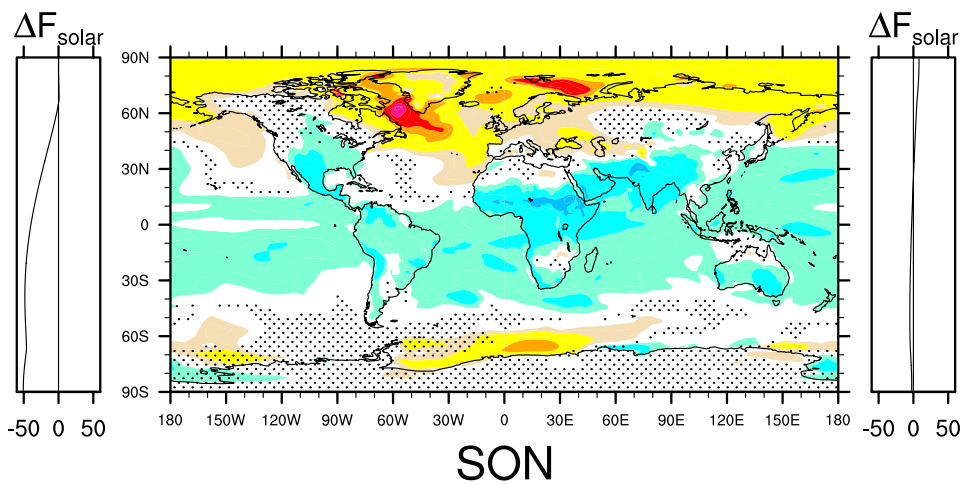

$\Delta \mathrm{F}_{\text {solar }}$
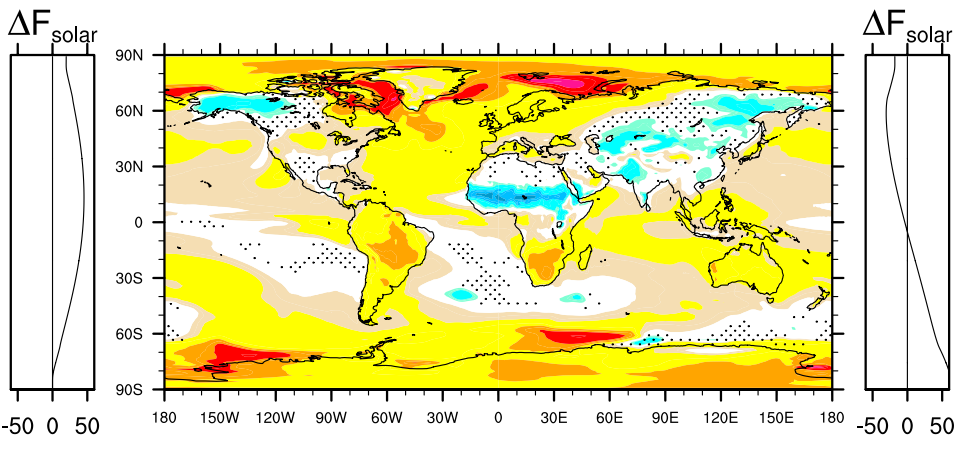

Fig. 3 Seasonal mean near-surface air temperature anomalies LIG-PI [K]. Shading denotes changes that are not significant at the $95 \%$ confidence level. The attached panels show the seasonal insolation anomalies $\left[\mathrm{W} \mathrm{m}^{-2}\right]$. Note the irregular spacing of the color bar

\subsubsection{The polar regions}

Both polar regions experience substantial forcing from the LIG insolation changes, albeit naturally with different seasonal timing of the changes. Figure 1 reveals that the Arctic experiences a positive insolation anomaly which peaks near Northern Hemisphere summer solstice countered by a negative anomaly in the fall, i.e. an earlier onset of the polar night. The Antarctic experiences relatively similar insolation anomalies, but the insolation increase is during austral spring and the decrease during austral summer. From a cryospheric perspective, the insolation in the Arctic gives increased potential for summer melt and an earlier onset of the freezing period. In the same view, the Antarctic has decreased potential for summer melt, but an earlier onset of the melt period.

In accordance with the seasonal insolation differences, the sea ice response is varying between the two hemispheres (Fig. 4). The total Antarctic sea ice extent (i.e. the area bounded by the $15 \%$ concentration contour) is reduced throughout the year, but exhibits only a limited decrease in late austral summer and fall. The Arctic sea ice extent exhibits a very uniform decrease throughout the year (a reduction of approximately $2 \times 10^{6} \mathrm{~km}^{2}$ ), but with a slightly larger decrease during late summer and early fall (July-September). The sea ice concentration in the central Arctic remains almost unchanged; the reduced extent is primarily due to a northward retreat of the sea ice edge.

From the warming over the high northern latitudes and Europe (Fig. 3), it is evident that the summertime increase overwhelms the impact of the insolation reduction during fall: Despite the reduced insolation, substantial warming is seen across high northern latitudes during fall (September-October-November; SON). The continuation of warming after the summertime insolation increase is related to the increased melt of sea ice during summer, which reduces the sea ice extent throughout the year. The loss of sea ice impacts the surface energy budget by lowering the surface albedo and reducing the insulating layer between the ocean and the atmosphere (Stroeve et al. 2012). During summer, the heat uptake by the ocean is increased following the insolation anomaly and the surface albedo feedback, which is more efficient due to the increased LIG insolation. In fall and winter, the sea ice reduction allows increased heat transfer from the ocean to the overlying atmosphere, and the heat flux is further strengthened by the anomalously warm ocean surface. The LIG experiment reveals a substantial increase of the turbulent heat flux upwards from the 


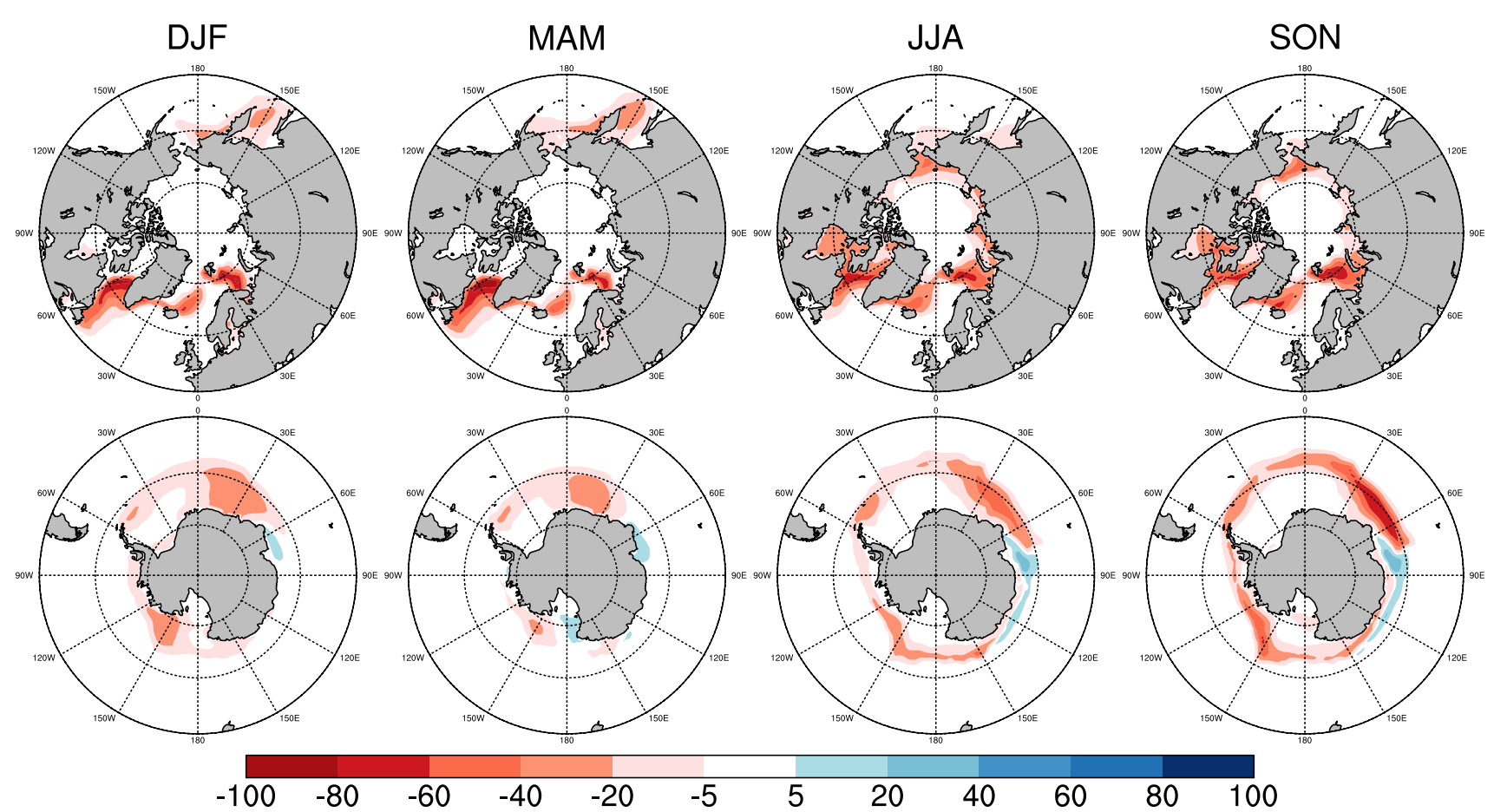

Fig. 4 LIG seasonal sea ice concentration anomalies compared to PI [\%]: Arctic (top row) and Antarctic (bottom row). Only anomalies larger than $5 \%$ concentration change are shown

ocean surface during fall (SON) and winter (DJF), which peaks in the areas of sea ice loss (not shown). This combined effect of the warmer ocean and loss of sea ice causes the sustained warming through fall and winter [as found by previous studies of Arctic sea ice loss (Vihma 2014; Pedersen et al. 2016a)]. Tuenter et al. (2005) and Otto-Bliesner et al. (2013) have previously shown how increased summer insolation invokes a year-round sea ice loss that contributes to Arctic warming throughout the year.

Reduction of the sea ice thickness could also lead to increased heat flux from the ocean through reduced insulation effect (Gerdes 2006). However, while the sea ice thickness is substantially decreased in the Arctic in LIG, the heat flux over the sea ice covered areas is largely unchanged. Despite the large thinning, the sea ice thickness in the central Arctic remains about 2-4 m in LIG (4-6 m in PI) and thus still efficiently insulates the ocean from the atmosphere.

In the Antarctic, the mean temperature change follows the annual cycle of the insolation anomalies (Fig. 3). Over the continent, temperatures decrease about 1-3 K during summer (DJF), and increase by a similar magnitude (regionally more than $3 \mathrm{~K}$ ) during spring (SON). The Southern Ocean and Antarctic coastal seas show warming in selected regions throughout the year. The warming coincides geographically with regions of sea ice loss in all seasons except summer (cf. Figs. 3, 4) and is, again, accompanied by increases in the upward turbulent heat fluxes from the surface (not shown). The sea ice related warming does, however, only appear to have a limited impact over the Antarctic continent.

\subsubsection{The North Atlantic region}

Substantial warming is evident in the North Atlantic region throughout the year. Part of this warming is related to the northward retreat of the sea ice edge (Fig. 4) described above, and increased absorption of incoming sunlight during summer. Additionally, the maximum strength of the Atlantic Meridional Overturning Circulation (AMOC) is increased in LIG compared to PI, increasing the heat transport toward the North Atlantic; especially in the colder seasons when deep convection is active. The maximum annual mean overturning strength increases by $37 \%$ from $15.8 \mathrm{~Sv}$ in PI to $21.6 \mathrm{~Sv}$ in LIG (with standard deviations 1.03 and $1.27 \mathrm{~Sv}$, respectively). This increase is in line with the increase of approximately $30 \%$ found in previous, similar GCM simulations of $125 \mathrm{ka}$ (Govin et al. 2012; Langebroek and Nisancioglu 2014).

Using the mixed layer depth as a proxy for deep water formation, Fig. 5 indicates that the main AMOC changes are related to the activation of convection in the Labrador Sea, where no convection occurs in PI, and an increased sinking in the Greenland Sea (south of Svalbard). The lack 


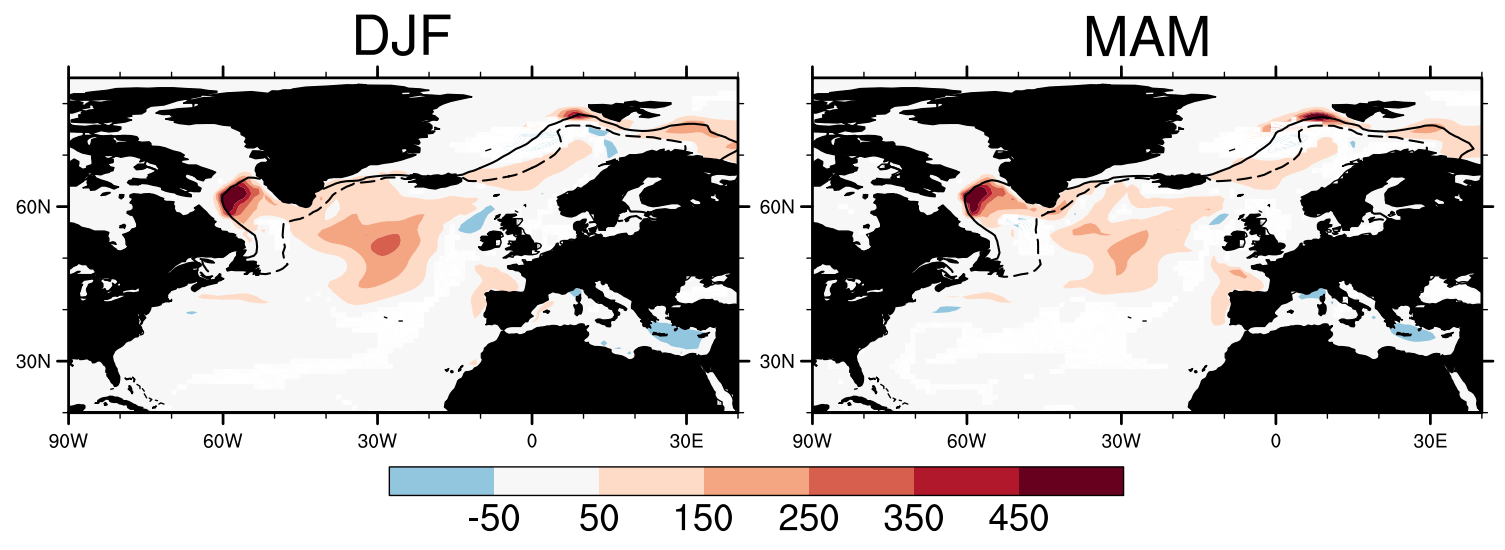

Fig. 5 Seasonal mean mixed layer depth anomalies LIG-PI [m] for winter (DJF) and spring (MAM), when convection is active. Black contours indicate sea ice extent (15\% concentration contour): PI

(dashed) and LIG (solid). Displayed changes are statistically significant at the $95 \%$ level

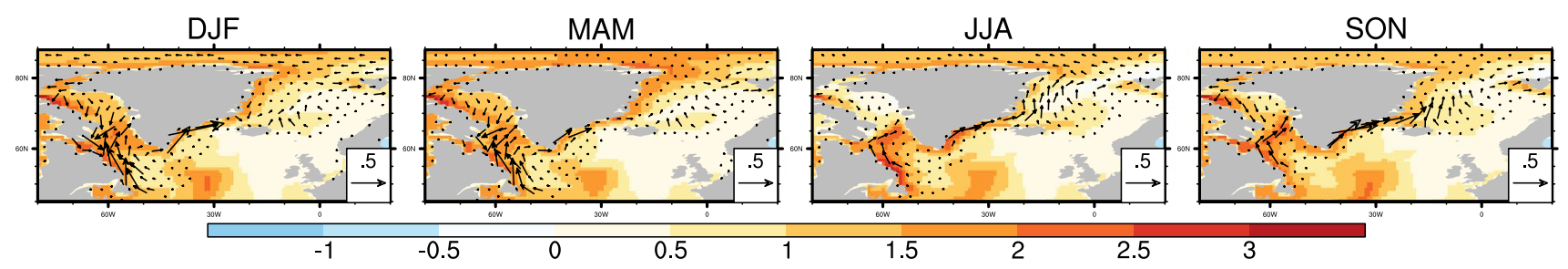

Fig. 6 Seasonal sea surface salinity anomaly [psu] in LIG compared to PI. Vectors indicate sea ice drift anomalies in LIG compared to PI $\left[\mathrm{km} \mathrm{h}^{-1}\right]$; unit vectors in the lower right corners correspond to $0.5 \mathrm{~km} \mathrm{~h}^{-1}$

of Labrador Sea convection in PI is likely related to model biases, as marine proxy records indicate active convection since the early part of the current interglacial (HillaireMarcel et al. 2001; Solignac et al. 2004).

Besides the changes in the Labrador Sea, the locations of deep water formation appear unchanged, but we observe an expansion of the convection areas following the northward retreat of the sea ice edge (as indicated by the mixed layer depths). The deep water formation is active from December to April with no substantial differences in the timing between PI and LIG (the northernmost areas have deepening of the mixed layer depth starting from November and ending in May).

The largest convection anomalies occur in connection with northward sea ice retreat in the North Atlantic region. The convection and the sea ice are interconnected, as the sea ice cover inhibits convection by insulating the ocean from the atmosphere, while the convection strength affects sea ice growth (retreat) through regional cooling (warming). Unfortunately, our experiments do not allow determination of the causality of the changes in the Labrador Sea region, i.e. whether the expanded sea ice cover in PI is the cause or the result of the convection shutdown.
We observe a general increase of the sea surface salinity (SSS) in the LIG experiment that is also consistent with the increased AMOC strength. The SSS affects the convection, which itself drives the circulation that brings saline water into the region (Stommel 1961; Kuhlbrodt et al. 2007). Hence, the increased AMOC would also favor increased salinity in the North Atlantic region, making it difficult to assess the causality pattern. One factor affecting SSS in the North Atlantic is the sea ice export southward from the Arctic Ocean (SSS and sea ice drift anomalies are shown in Fig. 6). In the LIG simulation the ice edge in the North Atlantic has retreated northward, and the changed sea ice drift indicates that the southward sea ice export through the Fram Strait and along the Greenland east coast is substantially decreased especially in summer and fall (as indicated by the northward drift anomaly vectors along the Greenland east coast in Fig. 6). The decreased sea ice export coincides with an increased SSS, e.g. along the Greenland east coast, in Baffin Bay and in the Labrador Sea. Sea ice export through the Fram Strait constitutes a substantial freshwater export southward from the Arctic Ocean (Serreze et al. 2006), and previous studies have illustrated that the sea ice export affects the salinity in the North Atlantic, 

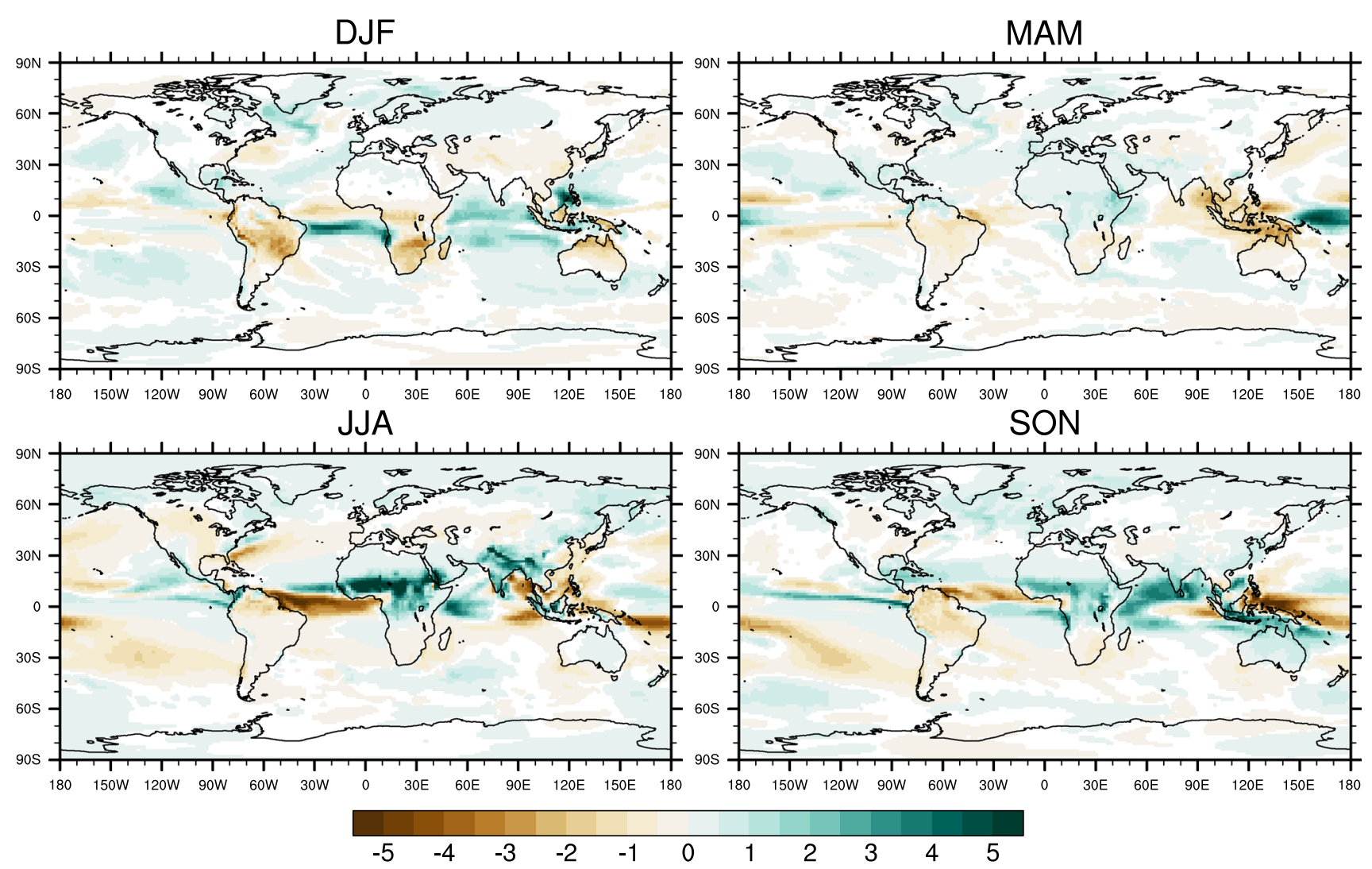

Fig. 7 LIG seasonal mean total precipitation (sum of convective and large scale precipitation) anomalies [mm pr. day]. Displayed changes are statistically significant at the $95 \%$ level

the Labrador Sea convection and AMOC strength (Born et al. 2010; Govin et al. 2012).

\subsubsection{The tropics}

The tropics $\left(30^{\circ} \mathrm{S}-30^{\circ} \mathrm{N}\right)$ experience an annual mean insolation reduction, but exhibit an almost unchanged annual mean temperature ( $0.02 \mathrm{~K}$ increase). Some tropical regions exhibit substantial cooling even in seasons without reduced insolation (Fig. 3), namely the sub-Saharan/Sahel region in Africa and, to lesser extent, India and parts of southeast Asia. The cooling effect is due to changes in cloudiness, soil moisture, and precipitation related to the monsoonal systems.

The North African monsoon has previously been shown to be sensitive to insolation changes (de Noblet et al. 1996; Braconnot et al. 2008; Govin et al. 2014; Bosmans et al. 2015). Specifically, the strength of the summer monsoon is increasing with anomalous high northern hemisphere summertime insolation (e.g. during LIG). The proposed mechanism (Braconnot et al. 2008; Bosmans et al. 2015) is that warming of the continents (by insolation during summer) increases ocean-land thermal and pressure gradients. The increased gradients and strengthened thermal low systems over land drive increased winds and moisture transport from the ocean to the continent. The precipitation increase is set up by a combination of increased moisture transport and local recycling (from evaporation); the latter being a minor contribution. The consequence is that the continental temperatures are expected to decrease due to increased cloud cover and evaporation (de Noblet et al. 1996; Montoya et al. 2000; Bosmans et al. 2015). Bosmans et al. (2015) investigate the links between insolation changes and the North African monsoon using the previous version of the EC-Earth model. Looking at the summer (JJA) means, the authors conclude that both low precession (summer solstice near perihelion) and high obliquity strengthens the monsoon by inducing a low pressure anomaly over Northern Africa which increases winds and moisture transport from the tropical Atlantic.

Consistent with the previous studies, the summertime (JJA) precipitation (Fig. 7) is increased substantially over the Indian and North African monsoon regions in the LIG. The precipitation increase coincides with increased cloud cover (not shown) and cooling (Fig. 3), consistent with an increased strength of the summer monsoonal systems. The total cloud fraction is increased by more than 0.2 in a broad band over the African continent covering approximately 
$5-25^{\circ} \mathrm{N}$, and the cloud increase is seen throughout the atmospheric column (i.e. both high, mid, and low clouds are increased). The atmospheric circulation anomaly (not shown) is very similar to the response outlined by Bosmans et al. (2015): Sea level pressure is substantially decreased over Northern Africa, and the anomalous circulation increases the flow from the tropical Atlantic towards the interior continent south of Sahara.

The circulation anomaly is only evident during summer (JJA), while the precipitation increase remains through the fall (SON). Some of the changes related to the summer monsoon even appear to persist throughout the year: near-surface cooling, increased surface evaporation, and increased cloud cover are dominant in the region all year, albeit in varying meridional extents. The increased cloud cover means that the down welling shortwave radiation at the surface is decreased throughout the year, regardless of the insolation anomaly (not shown). Thus, the monsoonal changes affect the hydrological cycle in the region and impact the climate the entire year. This is illustrated by the turbulent fluxes from the surface in the region: Fig. 8 shows the annual cycle of latent and sensible heat flux in the North African monsoonal region (here defined as $5^{\circ} \mathrm{S}-25^{\circ} \mathrm{N}$ and $20^{\circ} \mathrm{W}-40^{\circ} \mathrm{E}$ ). The latent heat flux is increased gradually during the summer monsoon season, and remains higher than PI through the fall. Evidently, the region is in a new regime where increased soil moisture allows more efficient cooling of the surface through evaporation, as illustrated by the increased latent heat flux. The colder surface consequently leads to a reduced sensible heat flux throughout the year. The wetter surface conditions combined with the increased cloud cover negates the impact of the summertime insolation increase on the surface.

\subsection{Separation of contributions}

The series of AGCM simulations is designed to investigate the mechanisms behind the simulated changes, and compare the direct and indirect effects of the insolation anomalies. Figure 9 displays the seasonal mean near-surface air temperature anomalies relative to iP $+\mathrm{oP}$ (PI conditions) in the three simulations (Table 2): $\mathrm{iL}+\mathrm{oL}$ (LIG conditions), iL + oP (LIG insolation, PI SST and sea ice), $\mathrm{iP}+\mathrm{oL}$ (PI insolation, LIG SST and sea ice), and iP $+\mathrm{oP}-$ ice (PI insolation, PI SST and LIG sea ice). As desired, the temperature anomaly in $\mathrm{iL}+\mathrm{oL}$ closely resembles the anomaly from the coupled experiment (compare with Fig. 3) over oceans as well as continents. The response in $\mathrm{iL}+\mathrm{oP}$ is limited to the continents (and sea ice covered areas), as the near-surface air temperature over the ocean is largely determined by the prescribed SSTs. Conversely, the iP + oL experiment reveals that the changed oceanic conditions have impacts across all continents even with

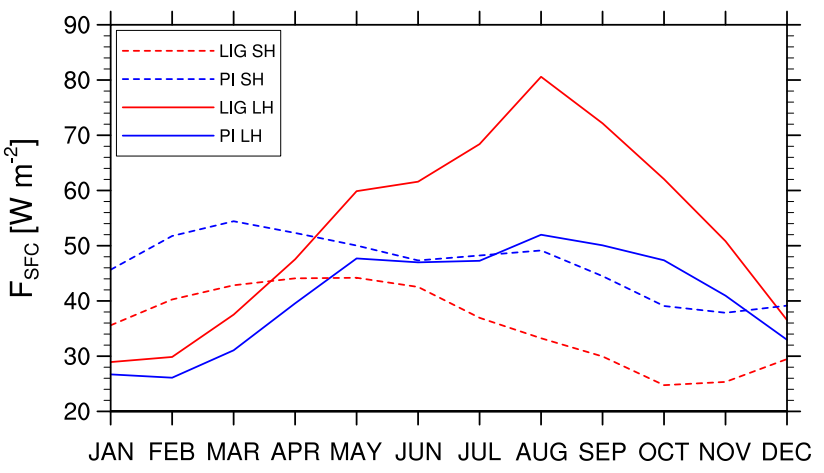

Fig. 8 Mean latent (solid lines) and sensible heat flux (dashed lines) in the North African monsoonal region (defined as $5^{\circ} \mathrm{S}-25^{\circ} \mathrm{N}$ and $20^{\circ} \mathrm{W}-40^{\circ} \mathrm{E}$ ): PI (blue) and LIG (red)

unchanged insolation. The iP + oP-ice experiment reveals that the sea ice reduction can explain a substantial part of the Arctic and Southern Ocean wintertime warming, even with unchanged SSTs.

The continental warming during the insolation maximum in Northern Hemisphere summer (JJA) is dominated by the direct impact of the insolation. The oceanic changes do, however, contribute to temperature increase over high northern latitudes and over Europe. The SST and sea ice changes appear to dominate the response over the same regions during fall and winter, where widespread warming occurs despite the lower insolation. Part of this allyear warming in the high northern latitudes, especially in the North Atlantic region including Greenland and Europe, can be ascribed to the AMOC increase and a seasonal memory of sea ice retreat [as described by Otto-Bliesner et al. (2013)]. In these regions, the oceanic changes more than outweigh the direct impact of the fall (SON) insolation decrease. The isolated impact of the sea ice loss (in $\mathrm{iP}+\mathrm{oP}-\mathrm{ice})$ is largely limited to the areas of sea ice retreat. One exception occurs during fall and winter where a more widespread Arctic warming is simulated. As the ice thickness is fixed in these simulations and no substantial concentration changes occur in the Arctic Ocean (Fig. 4), the widespread warming indicates that warming is advected from the ice loss regions. This is also manifested in the warming over Greenland. During winter (DJF) iP + oPice indicates that a substantial contribution to Greenland warming is related directly to the sea ice retreat (a detailed analysis of the Greenland response presented in Pedersen et al. 2016b). During summer (JJA in the Arctic, DJF in the Antarctic) there is no temperature response to the sea ice loss in $\mathrm{iP}+\mathrm{oP}$-ice. This is a direct consequence of the experiment design. In summer, the most dominant impact of sea ice loss is an albedo feedback that favors increased absorption of solar radiation that drives accelerated melt. As the SST is fixed, this effect is not captured in this setup. 

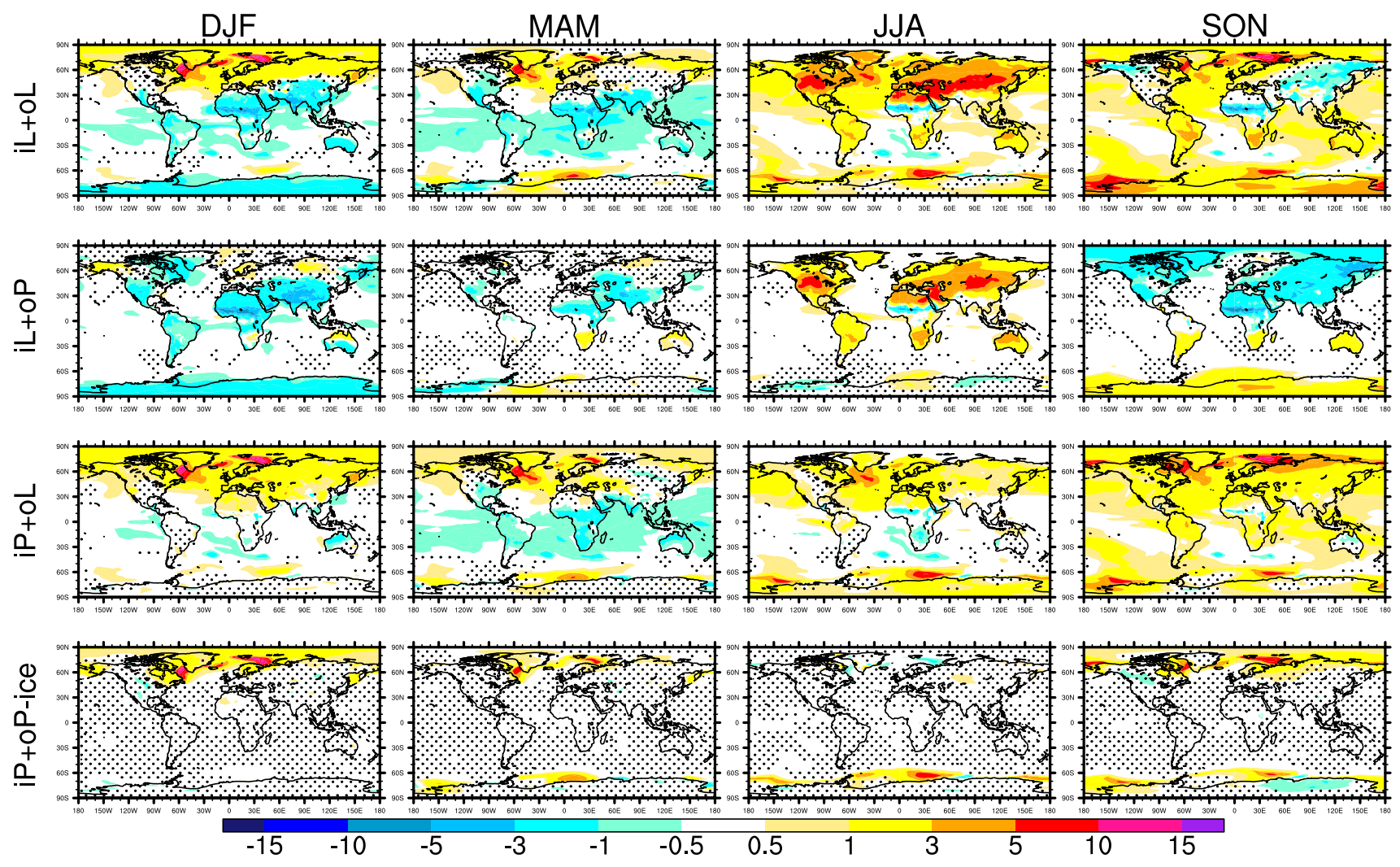

Fig. 9 Seasonal mean warming $[\mathrm{K}]$ in the AGCM experiments: $\mathrm{iL}+\mathrm{oL}$ (LIG conditions; top row), iL + oP (LIG insolation, PI SSTs; second row), iP + oL (PI insolation, LIG SSTs; third row), and $\mathrm{iP}+$ oP-ice (PI insolation, PI SSTs, LIG sea ice; bottom row).

In the Antarctic, reduced insolation dominates austral summer (DJF) temperatures that decrease over the entire continent. The warming from the oceanic changes spreads over most of the continent during both winter (JJA) and spring (SON). The strongest impact is during winter, with warming of more than $1 \mathrm{~K}$ over the majority of East Antarctica and about $0.5 \mathrm{~K}$ over West Antarctica. Increased spring (SON) insolation causes warming over the entire continent, while oceanic changes primarily impact the near-coastal regions in the vicinity of the sea ice loss in the Ross Sea $\left(150^{\circ} \mathrm{E}-90^{\circ} \mathrm{W}\right)$ and east of the Weddell Sea $\left(20^{\circ} \mathrm{W}-60^{\circ} \mathrm{E}\right)$. The resemblance of iP $+\mathrm{oL}$ and iP $+\mathrm{oP}-$ ice (Fig. 9) illustrates that the sea ice loss is the dominant cause of the warming near Antarctica.

Figure 9 shows high resemblance between the temperature response over the tropical region in $\mathrm{iL}+\mathrm{oL}$ and $\mathrm{iL}+\mathrm{oP}$ (insolation only). The contribution from the oceanic changes in iP $+\mathrm{oL}$ is warming Northern Africa through most of the year (except MAM), while also contributing to cooling over the Sahel region (except DJF). During SON the oceanic changes in $\mathrm{iP}+$ oL lead to significant warming over all continents, except Northern Australia and, again, the Sahel region in Africa.
All anomalies are relative to iP + oP (PI insolation, PI SSTs). Black shading marks anomalies that are not statistically significant at the $95 \%$ confidence level. Note the irregular spacing of the color bar

The precipitation changes reveal that both insolation and the related oceanic changes cause substantial changes in tropical precipitation patterns. Figure 10 shows the precipitation changes in JJA, where the seasonal anomalies over the continents are largest. As for the temperature anomalies, the precipitation anomalies in $\mathrm{iL}+\mathrm{oL}$ resemble the response in the coupled simulation. The hybrid simulations reveal that while the affected areas are similar in $\mathrm{iL}+\mathrm{oP}$ and $\mathrm{iP}+\mathrm{oL}$, the changes show large contrasts. In southeastern Asia, iL + oP exhibits wetter conditions over the continent at the expense of the near-coastal waters in the Indian and Pacific Oceans. The $\mathrm{iP}+\mathrm{oL}$ simulation exhibits precipitation increase over the same ocean regions (especially in the Indian Ocean) while no substantial changes are seen over the continent. Similar results are found in this region by previous studies of the Mid-Holocene, where the oceanic changes were even found to limit the continental precipitation increase driven by insolation changes (Liu et al. 2004; Braconnot et al. 2007). Substantial evaporation changes over the Indian Ocean (not shown) contribute to the varying precipitation changes between $\mathrm{iL}+\mathrm{oP}$ and $\mathrm{iP}+\mathrm{oL}$ : The insolation change in $\mathrm{iL}+\mathrm{oP}$ reduces the JJA mean evaporation in the region, while it is increased in $\mathrm{iP}+\mathrm{oL}$ coincident with the higher SSTs. 


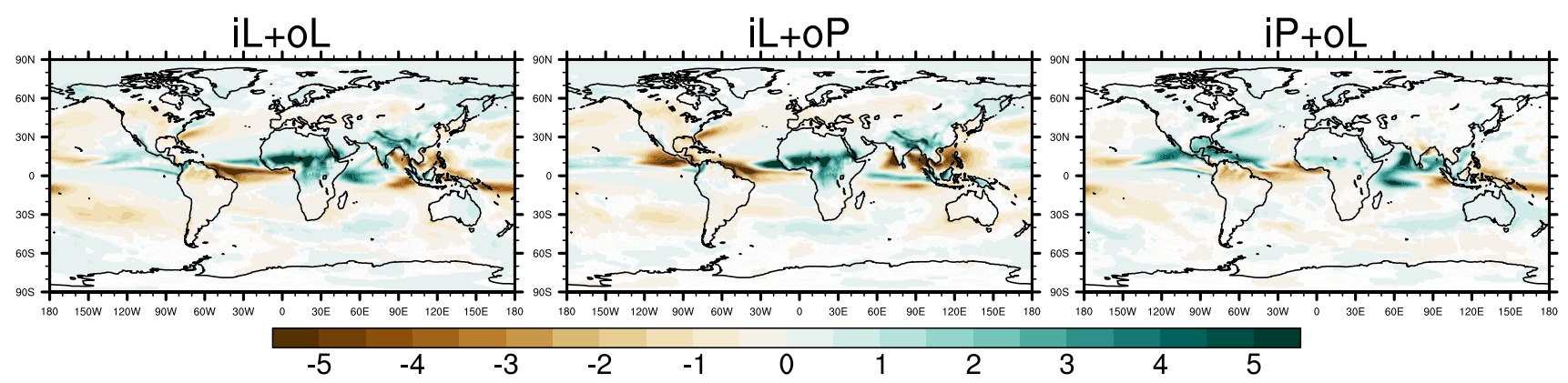

Fig. 10 JJA mean total (convective and large-scale) precipitation anomalies [mm pr. day] relative to iP $+\mathrm{oP}$ : $\mathrm{iL}+\mathrm{oL}(l e f t)$, iL $+\mathrm{oP}($ center $)$, and $\mathrm{iP}+\mathrm{oL}($ right $)$. Displayed changes are statistically significant at the $95 \%$ confidence level

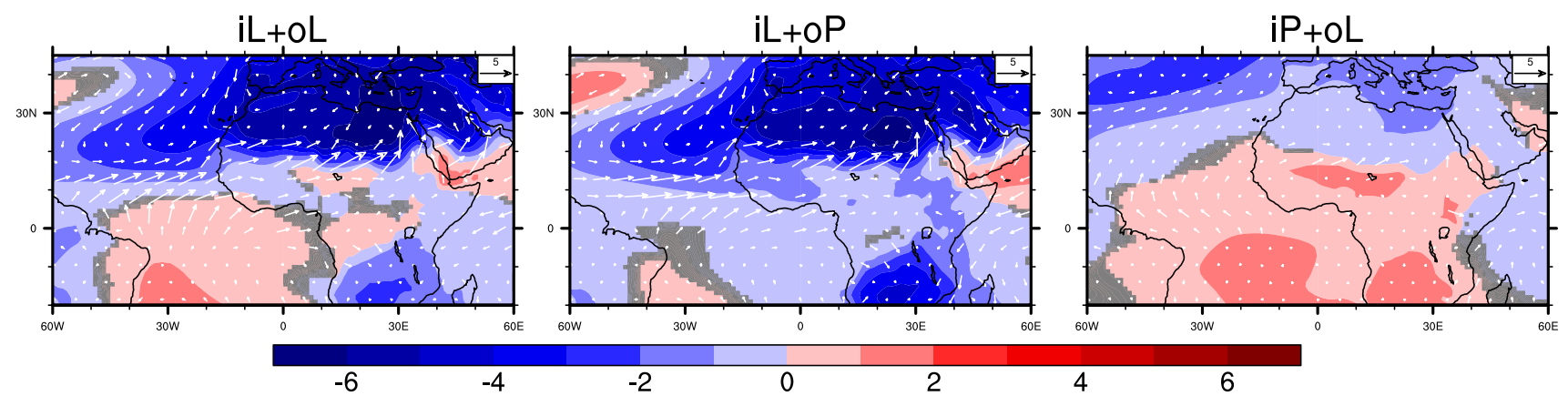

Fig. 11 June-July-August (JJA) mean sea level pressure anomalies $[\mathrm{hPa}]$ relative to $\mathrm{PP}+\mathrm{oP}: \mathrm{iL}+\mathrm{oL}$ (left), $\mathrm{iL}+\mathrm{oP}$ (center), and $\mathrm{iP}+\mathrm{oL}($ right). White arrows indicate wind $(10 \mathrm{~m})$ anomalies (unit

On both the Pacific and Atlantic sides of Central America, contrasting changes are seen in $\mathrm{iL}+\mathrm{oP}$ and $\mathrm{iP}+\mathrm{oL}$ : The insolation changes cause decreased rainfall, while the oceanic changes alone cause a substantial increase. The result from $\mathrm{iL}+\mathrm{oL}$ indicates that the combined response is close to the sum of the two, with only a slight increase on the Pacific side. In the Atlantic, similar contrasting changes are evident off the North American coast (co-located with the North Atlantic current), where the drier conditions from $\mathrm{iL}+\mathrm{oP}$ dominate in iL $+\mathrm{oL}$. In the tropical Atlantic both $\mathrm{iL}+\mathrm{oP}$ and $\mathrm{iP}+\mathrm{oL}$ show a belt of drier conditions from South America to Africa, but iL + oP also has a substantial precipitation increase off the African coast.

The strengthening of the Northern African monsoon discussed previously appears to be related directly to the insolation changes in iL + oP rather than the oceanic changes in iP $+\mathrm{oL}$. Nevertheless, the oceanic changes in $\mathrm{iP}+\mathrm{oL}$ do seem to contribute to the increased precipitation, albeit in smaller extent and magnitude. This is in line with the mechanism described above (suggested by Braconnot et al. 2008; Bosmans et al. 2015). Figure 11 presents the circulation changes in terms of mean sea level pressure and $10 \mathrm{~m}$ winds, and reveals high resemblance between the full response in $\mathrm{iL}+\mathrm{OL}$ and $\mathrm{iL}+\mathrm{oP}$. As described above, vector is $5 \mathrm{~m} \mathrm{~s}^{-1}$ ). Grey shading marks sea level pressure anomalies that are not statistically significant at the $95 \%$ confidence level

the insolation changes set up a low pressure anomaly over Northern Africa, which increases the flow and thus the moisture transport from the tropical Atlantic across the continent. These experiments indicate that the changes in Atlantic SSTs do not play a major role in shaping the monsoon response.

\section{Comparison to proxy records}

By comparing the simulated climate to proxy records, we aim to assess the model performance in simulating this paleoclimatic state. The comparison will further aid the assessment of the important mechanisms and the impacts of processes not included in this model setup. Following the results presented in the previous section, we will compare the simulated response to proxy records for temperature, North Atlantic ocean circulation, sea ice cover, and North African precipitation.

Capron et al. (2014) have compiled a collection of temperature proxy records covering the last interglacial. The dataset consists of several time slices; including $125 \mathrm{ka}$ employed here. While being based on a smaller number of records, it benefits from having a coherent temporal 

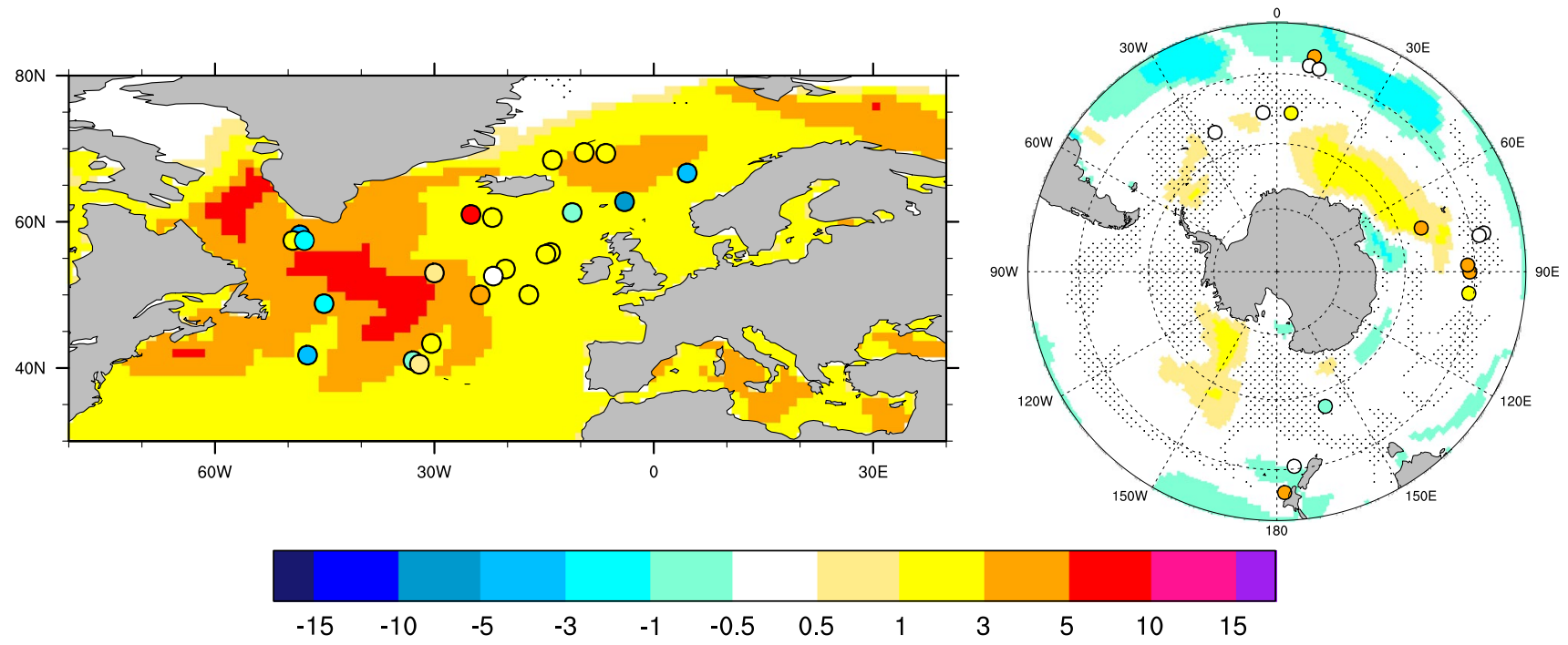

Fig. 12 LIG SST anomalies [K] compared to temperature reconstructions compiled by Capron et al. (2014). Left North Atlantic region summer (JAS) anomalies; Right Antarctic region summer (JFM) anomalies. Black shading denotes anomalies that are not sig-

framework compared to previous compilations (Turney and Jones 2010; McKay et al. 2011) which assume a worldwide synchronous peak warmth. Several studies have indicated that the timing of the last interglacial warming varies substantially across the globe (Govin et al. 2012; Bakker et al. 2013), and as highlighted by Bakker and Renssen (2014) the 'synchronous warming' assumption behind the previous data compilations contributes to model-data mismatch. Thus, we have preferred the Capron et al. (2014) dataset for model-data comparison due to the consistent dating; despite the more limited spatial coverage.

In order to compare our simulated anomalies to the proxy data reconstructions, the data from Capron et al. (2014) must be recalculated to account for the difference between the present-day reference climate used for the compilation (obtained from the 1998 World Ocean Atlas; WOA98) and the pre-industrial reference climate used here. Following the recommendations by Capron et al. (2014), we have accounted for this discrepancy by using the mean of the first 30 years of the HadISST dataset (1870-1899; Rayner et al. 2003) as representative of the pre-industrial. The difference between the HadISST pre-industrial estimate and the WOA98 data has been added to the proxyderived changes.

Figure 12 compares simulated SST changes to the proxy data compiled by Capron et al. (2014). The simulated summertime (here defined as July-August-September mean [JAS] to be consistent with the proxy data) conditions in the North Atlantic exhibit more widespread warming than suggested by the proxy data. Several proxy records even suggest cooling, contrasting the overall warming in our nificant at the $95 \%$ confidence level. Note the irregular color bar. Locations of overlapping records near $58^{\circ} \mathrm{N}, 48^{\circ} \mathrm{W}$ have been shifted slightly to make all records visible

simulations. These are found near the Norwegian Sea and in the area south of Greenland. The contrast is largest in the latter, where our simulations suggest substantial warming locally more than $5 \mathrm{~K}$. The warming during summer results from increased insolation during the earlier summer (in May, June, and July; Fig. 1), increased shortwave absorption due to sea ice loss, and the simulated AMOC increase.

Both the North Atlantic warming and the more limited warming near Antarctica appear to be general features across different GCMs (Lunt et al. 2013; Masson-Delmotte et al. 2013). We observe a fair qualitative agreement between the simulations and the proxy records, but the simulated warming is higher than the reconstructions in the North Atlantic, and the opposite applies near Antarctica.

The relatively large range between the proxies in the North Atlantic and Nordic Seas thus appears to be inconsistent with most modeling estimates, but previous studies have suggested that changes in the ocean circulation could explain these contrasting temperature trends (Bauch et al. 2012). Langebroek and Nisancioglu (2014) find regional cooling without addition of freshwater (using the NorESM model). Their simulations exhibit cooling during summer both in the central North Atlantic, related to an expansion of the subpolar gyre, and in the Norwegian Sea, due to reduced inflow of warm Atlantic water into the Nordic Seas. Hence, the characteristics of the ocean model potentially contributes to the regional model-data mismatch in the North Atlantic.

The pronounced difference between the ocean states in LIG and PI is likely affected by model biases (exemplified by the lack of Labrador Sea convection in PI). This 

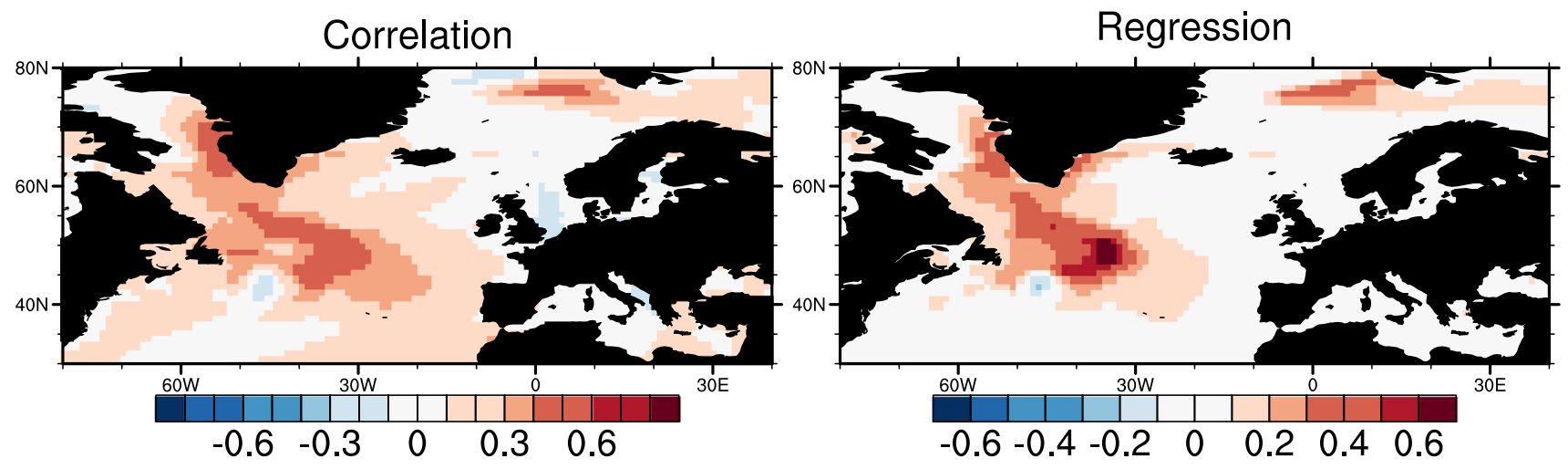

Fig. 13 Linear correlation coefficients (left) and linear regression coefficients $\left[\mathrm{K} \mathrm{Sv}^{-1}\right]$ (right) between annual mean maximum AMOC strength and the summer (JAS) SSTs in the LIG simulation

encourages a closer look at potential causes and impacts of the ocean circulation changes. The potential impact is assessed through correlation estimates which indicate that the AMOC increase contributes to widespread warming in the region, especially near the peak warming in the central North Atlantic (Fig. 13). Linear regression coefficients between the annual mean maximum AMOC strength and the JAS SSTs in the LIG simulation (Fig. 13) indicate that the region south of Greenland could warm by up to $0.5 \mathrm{~K} /$ Sv. Based on this estimate the AMOC increase in LIG could correspond to a local increase in JAS SST of up to $3 \mathrm{~K}$.

While the lack of Labrador Sea convection in PI disagrees with observations, it is less certain whether the Labrador deep convection was active during the last interglacial. Proxy data from marine sediment cores can be used to reconstruct the circulation patterns, but unfortunately there are some conflicting findings in this region. Hillaire-Marcel et al. (2001) question whether the Labrador Sea convection was active during the last interglacial, but Rasmussen et al. (2003) conclude the convection was active throughout the peak of the LIG and that the circulation was comparable to modern conditions. A third study by Winsor et al. (2012) find signs of reduced convection strength; at least during the early LIG.

Previous studies have found that inclusion of a meltwater flux from the expected reduction of the Greenland ice sheet could work to weaken the AMOC. In GCM simulations of the LIG (126 ka), Govin et al. (2012) show that the addition of meltwater from Greenland could even weaken the AMOC below the pre-industrial state. As the authors discuss, this finding is, however, an estimate of the highest potential effect of the GIS meltwater, as the flux of $0.17 \mathrm{~Sv}$ is very high compared to the expected GIS melt at $126 \mathrm{ka}$; a recent estimate suggests a meltwater flux of approximately $12.7 \mathrm{mSv}$ at $125 \mathrm{ka}$ (Blaschek et al. 2014). Sea level studies (e.g. Kopp et al. 2013) similarly indicate that sea level peaked near $125 \mathrm{ka}$ as the ice sheets were stabilizing, making it reasonable to exclude these changes from our model simulations.

The model treatment of the Arctic sea ice could impact the climate of the Arctic and North Atlantic regions. As noted above, the PI sea ice cover has an overall large extent and thickness (4-6 m in the central Arctic). While the sea ice thickness is poorly constrained before the modern epoch, submarine data from the middle of the twentieth century suggests that the ice thickness in the central Arctic did not exceed $4 \mathrm{~m}$ (Kwok and Rothrock 2009). Hence, the model is likely simulating an excessive sea ice thickness in PI; suggesting that the same could apply during LIG. In their analysis of the sea ice thickness in the CMIP5 model ensemble, Stroeve et al. (2014) show that the sea ice thickness in (the previous version of) EC-Earth is in the high end of the CMIP5 ensemble.

While the central Arctic sea ice thickness is reduced in LIG, it remains thick compared to present-day observations (Stroeve et al. 2014) and the concentration remains unchanged in central Arctic (above $90 \%$ throughout the year). Knowledge of Arctic sea ice cover during the last interglacial is unfortunately limited to reconstructions from a few marine sediment cores. Nørgaard-Pedersen et al. (2007) analyze a marine sediment record from the central Arctic Ocean $\left(84.5^{\circ} \mathrm{N}, 74^{\circ} \mathrm{W}\right.$, north of Greenland and the Canadian archipelago). This region is currently characterized by the thickest, oldest ice in the Arctic, but the paleo-reconstruction indicates a reduced sea ice concentration during the last interglacial. The record cannot reveal whether the reduction is a general regional sea ice reduction or a local, polynya-like feature. Adler et al. (2009) study a marine sediment record from the opposite site of the Arctic Ocean $\left(79^{\circ} \mathrm{N}, 172^{\circ} \mathrm{W}\right.$, north of Siberia/Alaska) and find similar indications of low sea ice concentration; potentially reflecting seasonally ice free conditions. Compared to these proxy records, our simulations (in line with 
previous LIG GCM simulations, e.g. Otto-Bliesner et al. 2013) suggest a much higher sea ice concentration in the central Arctic.

The marine sediment records in the Capron et al. (2014) dataset are supplemented by five ice core records: one from Greenland and four from Antarctica. In Greenland, our simulation appears to underestimate the warming compared to the proxy records. Despite the relatively warm conditions simulated in the North Atlantic, the near-surface air temperature does not reach the $8 \mathrm{~K}( \pm 4 \mathrm{~K})$ warming suggested by the NEEM ice core record from Northeastern Greenland (NEEM community members 2013). This mismatch could be due to missing ice sheet elevation changes and/or changed precipitation seasonality; a detailed study of the response over Greenland is presented in Pedersen et al. (2016b).

In the Southern Hemisphere during austral summer (defined as January-February-March [JFM] to be consistent with the proxy records) the Capron et al. (2014) proxy records with the highest warming lie beyond the range simulated in the region (Fig. 12). The grouping of warm proxy reconstructions near the Davis Sea could be related to sea ice changes resembling the simulated warming west of these records. None of the proxies seem to agree with the cooling areas simulated in the northern part of the domain in Fig. 12. The insolation is decreased near Antarctica during austral summer and cannot directly explain the warming suggested by both proxies and simulations. Comparison of $\mathrm{iP}+\mathrm{oL}$ and $\mathrm{iP}+\mathrm{oP}$-ice indicates that sea ice changes, originating from increased melt during the insolation increase in spring ( $\mathrm{SON}$ ), is a key source of warming. Some of the proxy records suggesting warming are, however, likely located too far north to be directly related to sea ice changes. The four Antarctic ice core records included in the Capron et al. (2014) $125 \mathrm{ka}$ dataset indicate summertime (DJF) warming between 0.8 and $1.7 \mathrm{~K}$ compared to present-day. With the present-day reference applied by Capron et al. (2014), we consider these values as a conservative estimate of the LIG warming compared to the preindustrial. Even so, the simulations rather suggest cooling over the Antarctic continent consistent with the DJF insolation reduction.

The most prominent feature of the tropical LIG climate is the strengthening of the North African monsoon. Although we established a mechanism for the monsoon strengthening, we further examine whether the simulated changes are reflected in paleoclimate archives. Marine cores drilled near river deltas reflect the river discharge, and hence the amount of precipitation in the river catchment area. Several marine cores off the coast in Western Africa (Gingele et al. 1998; Govin et al. 2014) and the Mediterranean (Rossignol-Strick 1985) dating back to the LIG all indicate an increased African monsoon, consistent with the findings in this and previous paleomodelling studies.

As these experiments are idealized simulations, the limitations should be considered when interpreting the results. Noteworthy caveats are that the ice sheets and the vegetation are kept constant in our experiments. In line with the estimated 6-9 m sea level increase (Kopp et al. 2009; Dutton and Lambeck 2012; Masson-Delmotte et al. 2013; Dutton et al. 2015), the ice sheets must have been reduced compared to the present. Reconstructions of the Greenland and Antarctic ice sheets do, however, reveal large variability between different studies (Masson-Delmotte et al. 2013). Depending on the exact changes, the reduced ice sheets could impact climate locally and potentially affect the large scale atmospheric circulation and thereby also the ocean circulation (Lunt et al. 2004; Petersen et al. 2004; Davini et al. 2015). Pfeiffer and Lohmann (2016) illustrate how a reduction of GrIS during LIG causes a strong local warming and weaker, more widespread regional warming, while ocean circulation changes drive substantial warming near the Antarctic coast. Merz et al. (2014), however, find a very stable response of the large-scale circulation in their AGCM simulations with a variety of last interglacial Greenland ice sheet reconstructions. For Antarctica, previous studies indicate that reduction of the West Antarctic ice sheet could cause additional local warming over the Antarctic continent (Overpeck et al. 2006; Holden et al. 2010; Otto-Bliesner et al. 2013).

Multiple sources indicate the LIG climate favored substantial vegetation changes compared to the pre-industrial. Proxy records from the Arctic region indicate a general northward shift in the vegetation types: The Arctic and sub-Arctic tundra was replaced by boreal and deciduous forest which regionally extended to the coast of the Arctic Ocean (Lozhkin and Anderson 1995; Edwards et al. 2003). Climate-vegetation models of varying complexity find the same tendency (Harrison et al. 1995; Schurgers et al. 2007; Nikolova et al. 2013), along with an increased Arctic warming related to the expanded vegetation (Crucifix and Loutre 2002; Schurgers et al. 2007). The increased warming can be explained by the albedo impact of the changed vegetation. Replacing tundra or bare ground with forest leads to a decreased albedo that favors increased local warming throughout the year (Bonan et al. 1992). Especially relevant for the Arctic region, snow covered forest has a lower albedo compared to snow covered ground or lower vegetation (Betts and Ball 1997). Swann et al. (2010) further find that broad-leaf forest increases the downward longwave radiation (i.e. the greenhouse effect) through increased transpiration of water vapor. While this could further impact the Arctic region, Schurgers et al. (2007) conclude that the climatic impact of the vegetation mainly is related to albedo changes. Thus the fixed vegetation in our 
experiments is likely limiting the simulated warming, and as suggested by Lunt et al. (2013) the gap between model and proxy data could be reduced by including active vegetation responses in the classical GCM paleo experiments.

\section{Conclusion}

The EC-Earth coupled GCM simulation of the last interglacial climate exhibits an annual mean near-surface warming of $0.5 \mathrm{~K}$ compared to pre-industrial conditions. Our simulations at higher resolution thus exhibit an annual mean change in the high end of the ensemble of previous LIG simulations (Masson-Delmotte et al. 2013; Lunt et al. 2013). In agreement with previous studies, the temperature change over the continents follow the annual cycle of the insolation changes, but we find important regional exceptions: (1) the monsoonal regions in Africa and India exhibit cooling throughout the year, and (2) Greenland, Europe, and the Northern part of Asia exhibit warming throughout the year.

The results of the AGCM experiments illustrate the importance of the oceanic changes (sea ice and sea surface temperature changes) for the year-round warming over high northern latitudes and Europe. Comparing the two hybrid simulations, the oceanic conditions dominate the response at high latitudes, while the direct insolation impact dominates at lower latitudes.

Our results indicate that warming patterns in both the North Atlantic and the Southern Ocean are closely related to sea ice changes. The magnitude of warming due to sea ice changes in the Southern Ocean is consistent with proxy records, but the proxy records suggest a slightly different spatial pattern of warming. Sea ice loss also contributes to substantial warming in the North Atlantic region, while the simulated AMOC increase further contributes to the strong regional warming.

The North African and Indian summer monsoons are intensified during LIG, and consequent increases in cloud cover and evaporation contribute to year-round cooling in both regions; even during times of increased insolation. The AGCM experiments show the importance of the insolation change over land relative to the oceanic changes. Our experiments demonstrate that the monsoon intensification is related to large-scale circulation anomalies similar to results from previous studies (Braconnot et al. 2008; Bosmans et al. 2015). The hybrid AGCM experiments (iL + oP and $\mathrm{iP}+\mathrm{oL}$ ) yield contrasting precipitation changes in the tropics; the combined response in iL + oL closely resembles the sum of the two.

The simulated temperature change shows fair agreement with the marine proxy records from Capron et al. (2014). While the exact geographical distribution is different, the magnitude of warming in the different regions matches that of the proxy records. One exception is the reconstructed cooling in parts of the North Atlantic; our simulations suggest dominant warming throughout the region. These discrepancies could be related to the identified biases related to the sea ice cover or that this particular ocean model misrepresents the circulation changes behind the warming.

Acknowledgments The authors thank Qiong Zhang and Qiang Li, Stockholm University for their collaboration on EC-Earth. Acknowledgement is made for the use of ECMWF's computing and archive facilities in this research. The research leading to these results has received funding from the European Research Council under the European Union's Seventh Framework Programme (FP7/2007- 2013)/ ERC Grant Agreement 610055 as part of the ice2ice project. The authors acknowledge the support of the Danish National Research Foundation through the Centre for Ice and Climate at the Niels Bohr Institute.

Open Access This article is distributed under the terms of the Creative Commons Attribution 4.0 International License (http://creativecommons.org/licenses/by/4.0/), which permits unrestricted use, distribution, and reproduction in any medium, provided you give appropriate credit to the original author(s) and the source, provide a link to the Creative Commons license, and indicate if changes were made.

\section{References}

Adler RE, Polyak L, Ortiz JD et al (2009) Sediment record from the western Arctic Ocean with an improved late quaternary age resolution: HOTRAX core HLY0503-8JPC, Mendeleev Ridge. Glob Planet Change 68:18-29. doi:10.1016/j.gloplacha.2009.03.026

Bakker P, Renssen H (2014) Last interglacial model-data mismatch of thermal maximum temperatures partially explained. Clim Past 10:1633-1644. doi:10.5194/cp-10-1633-2014

Bakker P, Stone EJ, Charbit S et al (2013) Last interglacial temperature evolution-a model inter-comparison. Clim Past 9:605-619. doi:10.5194/cp-9-605-2013

Bakker P, Masson-Delmotte V, Martrat B et al (2014) Temperature trends during the present and last interglacial periodsa multi-model-data comparison. Quat Sci Rev 99:224-243. doi:10.1016/j.quascirev.2014.06.031

Bauch HA, Kandiano ES, Helmke JP (2012) Contrasting ocean changes between the subpolar and polar North Atlantic during the past $135 \mathrm{ka}$. Geophys Res Lett. doi:10.1029/201 2GL051800

Berger A (1978) Long-term variations of daily insolation and quaternary climatic changes. J Atmos Sci 35:2362-2367

Betts AK, Ball JH (1997) Albedo over the boreal forest. J Geophys Res 102:28901-28909. doi:10.1029/96JD03876

Blaschek M, Bakker P, Renssen H (2014) The influence of Greenland ice sheet melting on the Atlantic meridional overturning circulation during past and future warm periods: a model study. Clim Dyn. doi:10.1007/s00382-014-2279-1

Bonan GB, Pollard D, Thompson SL (1992) Effects of boreal forest vegetation on global climate. Nature 359:716-718. doi:10.1038/359716a0

Born A, Nisancioglu KH, Braconnot P (2010) Sea ice induced changes in ocean circulation during the Eemian. Clim Dyn 35:1361-1371. doi:10.1007/s00382-009-0709-2

Bosmans JHC, Drijfhout SS, Tuenter E et al (2015) Response of the North African summer monsoon to precession and 
obliquity forcings in the EC-Earth GCM. Clim Dyn 44:279-297. doi:10.1007/s00382-014-2260-z

Braconnot P, Otto-Bliesner BL, Harrison S et al (2007) Results of PMIP2 coupled simulations of the Mid-Holocene and Last Glacial Maximum-Part 1: experiments and large-scale features. Clim Past 3:261-277. doi:10.5194/cp-3-261-2007

Braconnot P, Marzin C, Gregoire L et al (2008) Monsoon response to changes in Earth's orbital parameters: comparisons between simulations of the Eemian and of the Holocene. Clim Past 4:281-294

Braconnot P, Harrison SP, Otto-Bliesner BL et al (2011) The Paleoclimate Modeling Intercomparison Project contribution to CMIP5. CLIVAR Exch 16:15-19

Braconnot P, Harrison SP, Kageyama M et al (2012) Evaluation of climate models using palaeoclimatic data. Nat Clim Chang 2:417424. doi:10.1038/nclimate 1456

CAPE-Last Interglacial Project Members (2006) Last Interglacial Arctic warmth confirms polar amplification of climate change. Quat Sci Rev 25:1383-1400. doi:10.1016/j.quascirev.2006.01.033

Capron E, Govin A, Stone EJ et al (2014) Temporal and spatial structure of multi-millennial temperature changes at high latitudes during the Last Interglacial. Quat Sci Rev 103:116-133. doi:10.1016/j.quascirev.2014.08.018

Clark PU, Huybers P (2009) Interglacial and future sea level. Nature 462:856-857

Crucifix M, Loutre M-F (2002) Transient simulations over the last interglacial period (126-115 kyr BP): feedback and forcing analysis. Clim Dyn 19:417-433. doi:10.1007/s00382-002-0234-z

Davini P, von Hardenberg J, Filippi L, Provenzale A (2015) Impact of Greenland orography on the Atlantic Meridional Overturning Circulation. Geophys Res Lett 42:871-879. doi:10.1002/20 14GL062668

de Noblet N, Braconnot P, Joussaume S, Masson V (1996) Sensitivity of simulated Asian and African summer monsoons to orbitally induced variations in insolation 126, 115 and $6 \mathrm{kBP}$. Clim Dyn 12:589-603. doi:10.1007/s003820050130

Dutton A, Lambeck K (2012) Ice volume and sea level during the last interglacial. Science 337:216-219. doi:10.1126/science.1205749

Dutton A, Carlson AE, Long AJ et al (2015) Sea-level rise due to polar ice-sheet mass loss during past warm periods. Science. doi:10.1126/science.aaa4019

Edwards M, Hamilton T, Elias S et al (2003) Interglacial extension of the Boreal forest limit in the Noatak Valley, Northwest Alaska: evidence from an Exhumed River-Cut Bluff and Debris Apron. Arctic Antarct Alp Res 35:460-468. doi:10.1657/1523-0430(2003)035[0460:IEOTBF]2.0.CO;2

European Centre for Medium-Range Weather Forecasts (2010) CY36R1 Official IFS Documentation. https://software.ecmwf. int/wiki/display/IFS/CY36R1+Official+IFS+Documentation. Accessed 9 Mar 2016

Fischer N, Jungclaus JH (2010) Effects of orbital forcing on atmosphere and ocean heat transports in Holocene and Eemian climate simulations with a comprehensive Earth system model. Clim Past 6:155-168. doi:10.5194/cp-6-155-2010

Gerdes R (2006) Atmospheric response to changes in Arctic sea ice thickness. Geophys Res Lett. doi:10.1029/2006GL027146

Gingele FX, Müller PM, Schneider RR (1998) Orbital forcing of freshwater input in the Zaire Fan area-clay mineral evidence from the last 200 kyr. Palaeogeogr Palaeoclimatol Palaeoecol 138:17-26. doi:10.1016/S0031-0182(97)00121-1

Govin A, Braconnot P, Capron E et al (2012) Persistent influence of ice sheet melting on high northern latitude climate during the early Last Interglacial. Clim Past 8:483-507. doi:10.5194/ cp-8-483-2012

Govin A, Varma V, Prange M (2014) Astronomically forced variations in western African rainfall $(20 \mathrm{~N}-20 \mathrm{~S})$ during the
Last Interglacial Period. Geophys Res Lett. doi:10.1002/201 3GL058954

Govin A, Capron E, Tzedakis PC et al (2015) Sequence of events from the onset to the demise of the Last Interglacial: evaluating strengths and limitations of chronologies used in climatic archives. Quat Sci Rev 129:1-36. doi:10.1016/j.quascirev.2015.09.018

Harrison SP, Kutzbach JE, Prentice IC et al (1995) The response of northern hemisphere extratropical climate and vegetation to orbitally induced changes in insolation during the last interglaciation. Quat Res 43:174-184

Hazeleger W, Severijns C, Semmler T et al (2010) EC-Earth: a seamless earth-system prediction approach in action. Bull Am Meteorol Soc. doi:10.1175/2010BAMS2877.1

Hazeleger W, Wang X, Severijns C et al (2012) EC-Earth V2.2: description and validation of a new seamless earth system prediction model. Clim Dyn 39:2611-2629. doi:10.1007/ s00382-011-1228-5

Hillaire-Marcel C, de Vernal A, Bilodeau G, Weaver AJ (2001) Absence of deep-water formation in the Labrador Sea during the last interglacial period. Nature 410:1073-1077. doi: $10.1038 / 35074059$

Holden PB, Edwards NR, Wolff EW et al (2010) Interhemispheric coupling, the West Antarctic Ice Sheet and warm Antarctic interglacials. Clim Past 6:431-443. doi:10.5194/cp-6-431-2010

Joussaume S, Braconnot P (1997) Sensitivity of paleoclimate simulation results to season definitions. J Geophys Res 102:1943-1956

Kopp RE, Simons FJ, Mitrovica JX et al (2009) Probabilistic assessment of sea level during the last interglacial stage. Nature 462:863-867. doi:10.1038/nature08686

Kopp RE, Simons FJ, Mitrovica JX et al (2013) A probabilistic assessment of sea level variations within the last interglacial stage. Geophys J Int 193:711-716. doi:10.1093/gji/ggt029

Kuhlbrodt T, Griesel A, Montoya M et al (2007) On the driving processes of the Atlantic meridional overturning circulation. Rev Geophys. doi:10.1029/2004RG000166

Kwok R, Rothrock DA (2009) Decline in Arctic sea ice thickness from submarine and ICESat records: 1958-2008. Geophys Res Lett. doi:10.1029/2009GL039035

Langebroek PM, Nisancioglu KH (2014) Simulating last interglacial climate with NorESM: role of insolation and greenhouse gases in the timing of peak warmth. Clim Past 10:1305-1318. doi:10.5194/cp-10-1305-2014

Liu Z, Harrison SP, Kutzbach J, Otto-Bliesner BL (2004) Global monsoons in the mid-Holocene and oceanic feedback. Clim Dyn 22:157-182. doi:10.1007/s00382-003-0372-y

Lozhkin AV, Anderson PM (1995) The Last Interglaciation in Northeast Sibera. Quat Res. 43:147-158

Lunt DJ, de Noblet-Ducoudré N, Charbit S (2004) Effects of a melted greenland ice sheet on climate, vegetation, and the cryosphere. Clim Dyn 23:679-694. doi:10.1007/s00382-004-0463-4

Lunt DJ, Abe-Ouchi A, Bakker P et al (2013) A multi-model assessment of last interglacial temperatures. Clim Past 9:699-717. doi:10.5194/cp-9-699-2013

Madec G (2011) Nemo Ocean Engine (version 3.3). Note du Pôle de modélisation de 1'Institut Pierre-Simon Laplace No 27. ISSN No 1288-1619. http://www.nemo-ocean.eu/Media/Files/NEMO_ book_V3_3.pdf. Accessed 8 Jan 2016

Masson-Delmotte V, Schulz M, Abe-Ouchi A, et al (2013) Information from Paleoclimate Archives. In: Stocker TF, Qin D, Plattner G-K et al. (eds) Climate Change 2013: The physical science basis. Contribution of working group I to the fifth assessment report of the intergovernmental panel on climate change. Cambridge University Press, Cambridge, pp 383-464

McKay NP, Overpeck JT, Otto-Bliesner BL (2011) The role of ocean thermal expansion in Last Interglacial sea level rise. Geophys Res Lett. doi:10.1029/2011GL048280 
Merz N, Born A, Raible CC et al (2014) Dependence of Eemian Greenland temperature reconstructions on the ice sheet topography. Clim Past 10:1221-1238. doi:10.5194/cp-10-1221-2014

Montoya M, von Storch H, Crowley TJ (2000) Climate simulation for $125 \mathrm{kyr}$ BP with a coupled ocean-atmosphere general circulation model. J Clim 13:1057-1072. doi:10.1175/1520-0442(2000)013<1057:CSFKBW>2.0.CO;2

Muschitiello F, Zhang Q, Sundqvist HS et al (2015) Arctic climate response to the termination of the African Humid period. Quat Sci Rev 125:91-97. doi:10.1016/j.quascirev.2015.08.012

NEEM community members (2013) Eemian interglacial reconstructed from a Greenland folded ice core. Nature 493:489-494. doi:10.1038/nature11789

Nikolova I, Yin Q, Berger A et al (2013) The last interglacial (Eemian) climate simulated by LOVECLIM and CCSM3. Clim Past 9:1789-1806. doi:10.5194/cp-9-1789-2013

Nørgaard-Pedersen N, Mikkelsen N, Lassen SJ et al (2007) Reduced sea ice concentrations in the Arctic Ocean during the last interglacial period revealed by sediment cores off northern Greenland. Paleoceanography 22:1-15. doi:10.1029/2006PA001283

Otto-Bliesner BL, Marshall SJ, Overpeck JT et al (2006) Simulating Arctic climate warmth and icefield retreat in the last interglaciation. Science 311:1751-1753. doi:10.1126/science.1120808

Otto-Bliesner BL, Rosenbloom N, Stone EJ et al (2013) How warm was the last interglacial? New model-data comparisons. Philos Trans A Math Phys Eng Sci. doi:10.1098/rsta.2013.0097

Overpeck JT, Otto-Bliesner BL, Miller GH et al (2006) Paleoclimatic evidence for future ice-sheet instability and rapid sea-level rise. Science 311:1747-1750. doi:10.1126/science.1115159

Pedersen RA, Cvijanovic I, Langen PL, Vinther BM (2016a) The impact of regional Arctic Sea Ice loss on atmospheric circulation and the NAO. J Clim 29:889-902. doi:10.1175/ JCLI-D-15-0315.1

Pedersen RA, Langen PL, Vinther BM (2016b) Greenland warming during the last interglacial: the relative importance of insolation and oceanic changes. Clim Past Discuss. doi:10.5194/ cp-2016-48

Petersen GN, Kristjánsson JE, Ólafsson H (2004) Numerical simulations of Greenland's impact on the Northern Hemisphere winter circulation. Tellus Ser A Dyn Meteorol Oceanogr 56:102-111. doi:10.1111/j.1600-0870.2004.00047.x

Pfeiffer M, Lohmann G (2016) Greenland Ice Sheet influence on Last Interglacial climate: global sensitivity studies performed with an atmosphere-ocean general circulation model. Clim Past 12:1313-1338. doi:10.5194/cp-12-1313-2016

PMIP3 (2010) Last interglacial experimental design. https://wiki.lsce. ipsl.fr/pmip3/doku.php/pmip3:design:li:final. Accessed 8 Jan 2016

Rasmussen TL, Oppo DW, Thomsen E, Lehman SJ (2003) Deep sea records from the southeast Labrador Sea: ocean circulation changes and ice-rafting events during the last 160,000 years. Paleoceanography 18:n/a-n/a. doi:10.1029/2001PA000736

Rayner NA, Parker DE, Horton EB et al (2003) Global analyses of sea surface temperature, sea ice, and night marine air temperature since the late nineteenth century. J Geophys Res. doi:10.1029/2 002JD002670

Rossignol-Strick M (1985) Mediterranean quaternary sapropels, an immediate response of the African monsoon to variation of insolation. Palaeogeogr Palaeoclimatol Palaeoecol 49:237-263. doi:10.1016/0031-0182(85)90056-2

Schurgers G, Mikolajewicz U, Gröger M et al (2007) The effect of land surface changes on Eemian climate. Clim Dyn 29:357-373. doi:10.1007/s00382-007-0237-x

Serreze MC, Barry RG (2011) Processes and impacts of Arctic amplification: a research synthesis. Glob Planet Change 77:85-96. doi:10.1016/j.gloplacha.2011.03.004

Serreze MC, Barrett AP, Slater AG et al (2006) The large-scale freshwater cycle of the Arctic. J Geophys Res. doi:10.1029/200 5JC003424

Solignac S, De Vernal A, Hillaire-Marcel C (2004) Holocene seasurface conditions in the North Atlantic-contrasted trends and regimes in the western and eastern sectors (Labrador Sea vs. Iceland Basin). Quat Sci Rev 23:319-334. doi:10.1016/j. quascirev.2003.06.003

Stommel HM (1961) Thermohaline convection with two stable regimes of flow. Tellus 13:224-230. doi:10.1111/j.2153-3490.1961.tb00079.x

Stroeve JC, Serreze MC, Holland MM et al (2012) The Arctic's rapidly shrinking sea ice cover: a research synthesis. Clim Change 110:1005-1027. doi:10.1007/s10584-011-0101-1

Stroeve JC, Barrett AP, Serreze MC, Schweiger A (2014) Using records from submarine, aircraft and satellites to evaluate climate model simulations of Arctic sea ice thickness. Cryosphere 8:1839-1854. doi:10.5194/tc-8-1839-2014

Swann AL, Fung IY, Levis S et al (2010) Changes in Arctic vegetation amplify high-latitude warming through the greenhouse effect. Proc Natl Acad Sci 107:1295-1300. doi:10.1073/ pnas.0913846107

Tuenter E, Weber SL, Hilgen FJ, Lourens LJ (2005) Sea-ice feedbacks on the climatic response to precession and obliquity forcing. Geophys Res Lett. doi:10.1029/2005GL024122

Turney CSM, Jones RT (2010) Does the Agulhas current amplify global temperatures during super-interglacials? J Quat Sci 25:839-843. doi:10.1002/jqs.1423

Vancoppenolle M, Fichefet T, Goosse H et al (2009) Simulating the mass balance and salinity of Arctic and Antarctic sea ice. 1. Model description and validation. Ocean Model 27:33-53. doi:10.1016/j.ocemod.2008.10.005

Vihma T (2014) Effects of Arctic sea ice decline on weather and climate: a review. Surv Geophys 35:1175-1214. doi:10.1007/ s10712-014-9284-0

von Storch H, Zwiers FW (2001) Statistical analysis in climate research. Cambridge University Press, Cambridge

Winsor K, Carlson AE, Klinkhammer GP et al (2012) Evolution of the northeast Labrador Sea during the last interglaciation. Geochem Geophys Geosyst. doi:10.1029/2012GC004263 